\title{
On Decomposing Inflection Class Features: Syncretism in Russian Noun Inflection
}

\author{
Gereon Müller*
}

\section{Introduction}

Inflection class features that assign noun stems to declensional classes are peculiar objects. On the one hand, nominal inflection class features seem to be indispensable in analyses of noun inflection systems in various IndoEuropean languages (like Spanish, Greek, and Russian). On the other hand, nominal inflection class features differ from other, well-established morphological features (like case, gender, and number features) in two important respects that (at least at first sight) shed doubt on their existence. First, inflection class features are much more abstract than, say, case, gender, or number features; they are not grounded in any way, and they are not independently motivated. Second, inflection class features do not seem to play any role in the syntax, again in contrast to features like case, gender, and number, which syntactic operations may refer to. In view of this state of affairs, one may try to avoid inflection class features in analyses of noun inflection altogether; but given the insurmountable difficulties that arise in such an enterprise, I take it that any such attempt is doomed to fail. Another option (the one that is standardly adopted) is to simply accept, as an imperfection in grammar design, the existence of inflection class features as irreducible objects.

Based on empirical evidence from noun inflection in Russian, I will pursue a third strategy in this article, which is to strengthen the role of inflection

\footnotetext{
${ }^{*}$ For helpful comments and discussion, I would like to thank Artemis Alexiadou, John Bailyn, Loren Billings, Johnathan Bobaljik, Wayles Browne, Steven Franks, Lutz Gunkel, Jadranka Gvozdanović, Fabian Heck, Milan Rezac, Anita Steube, Arnim von Stechow, Anna Volodina, Gisela Zifonun, Ilse Zimmermann, the participants of Dieter Wunderlich's farewell colloquium (Universität Düsseldorf, June 28, 2002), the audiences of FASL 12 (University of Ottawa, May 9, 2003) and FDSL 5 (Universität Leipzig, November 26, 2003), and especially Bernd Wiese and Dieter Wunderlich.
}

Explorations in Nominal Inflection, 189-227

Gereon Müller, Lutz Gunkel, \& Gisela Zifonun (eds.)

Copyright (c) 2004, Mouton de Gruyter, Berlin 
class features: If one cannot get rid of inflection class features, one may as well promote them to a more prominent position, and let them do more work in morphology than has previously been assumed. I will argue that inflection class features can be decomposed into more primitive features (as has been suggested for case features (see Jakobson (1962a), Bierwisch (1967)) and that doing so offers a straightforward explanation of instances of transparadigmatic syncretism, i.e., syncretism that holds across inflection classes. Trans-paradigmatic syncretism in Russian noun inflection has, to the best of my knowledge, not yet been derived in a principled way (in contrast to intraparadigmatic syncretism, i.e., syncretism that holds within an inflection class, which has been accounted for by decomposing case features). Furthermore, I will argue that decomposed inflection class features play a role in morphology that is analogous to the role played by uninterpretable features in syntax in the system of Chomsky $(1995 ; 2000 ; 2001)$ : Being uninterpretable in the syntactic component, inflection class features drive morphological operations that delete them before syntax is reached. Thus, these features turn out not to be an imperfection after all. This reasoning will provide an argument against late insertion in a minimalist grammar.

I will proceed as follows. In section 2, I present the main paradigms of noun inflection in Russian and show that inflection class features are necessary to account for them. In section 3, I turn to the issue of syncretism in Russian noun inflection. I show that by decomposing both case and inflection class features into more primitive features, most instances of intraparadigmatic and trans-paradigmatic syncretism (i.e., syncretism within and across inflection classes) can systematically be accounted for, in interaction with the Specificity Condition. In section 4, I address the general role of inflection class features in grammar, and argue that they can be conceived of as the sole triggers of inflection with portmanteau markers.

\section{Noun Inflection in Russian}

\subsection{Data}

Let me begin with the paradigms of Russian noun inflection, focussing on the singular for the time being. ${ }^{1}$ I will assume that there are four noun in-

\footnotetext{
${ }^{1}$ Throughout this article, I adopt the view that paradigms do not exist as genuine objects that morphological operations can refer to, or that meta-constraints can be imposed on. Rather,
} 
flection classes in Russian (I-IV), which give rise to four paradigms which will be referred to as $\mathrm{P}_{1}-\mathrm{P}_{4}{ }^{2}$ The markers of inflection class I for the six cases of Russian (nominative, accusative, dative, genitive, instrumental, and locative) are shown in paradigm $\mathrm{P}_{1}$. All nouns that take markers from this class are masculine. There is some principled variation: Inanimate nouns have identical markers for nominative and accusative case (viz., a marker that is phonologically null, rendered here as Ø); animate nouns exhibit a syncretism of markers for accusative and genitive case (compare zavod- ('factory') and student- ('student')). Furthermore, in the instrumental there is a difference between nouns whose stems ends in a "hard" (i.e., [+back]) consonant and nouns whose stem ends in a "soft" (i.e., [-back]) consonant: The former have om as the instrumenal case marker, the latter em (compare student-om with žitel-em ('inhabitant')).

$P_{1}$ : Inflection class I, Sg.: masc

\begin{tabular}{|c|c|c|c|}
\hline & \multicolumn{3}{|c|}{ I } \\
\hline & $\operatorname{zavod}_{m}$ ('factory') & student $_{m}$ ('student') & žitel $_{m}$ ('inhabitant') \\
\hline $\mathrm{nom} / \mathrm{sg}$ & zavod- $\varnothing$ & student- $\varnothing$ & Žitel'-Ø \\
\hline $\mathrm{acc} / \mathrm{sg}$ & zavod- $\varnothing$ & student-a & žitel-ja \\
\hline $\mathrm{dat} / \mathrm{sg}$ & zavod-u & student-u & žitel-ju \\
\hline gen/sg & zavod-a & student-a & žitel-ja \\
\hline inst/sg & zavod-om & student-om & Žitel-em \\
\hline loc/sg & zavod-e & student-e & Žitel-e \\
\hline
\end{tabular}

paradigms will be considered to be pure epiphenomena, i.e., generalizations that can be derived from more basic assumptions. I take it that this view is directly supported by the system of Russian noun inflection, which has been argued to pose problems for meta-constraints that presuppose the existence of paradigms. For instance, Bobaljik (2002) shows that Russian noun inflection contradicts the Instantiated Basic Paradigm restriction suggested in Williams (1994), and Stump (2001, 224ff.) argues that Russian noun inflection raises problems for the Paradigm Economy Principle proposed in Carstairs (1987) (also see Carstairs-McCarthy (1998)). - That said, most of what follows would be compatible with theories of inflectional morphology that rely on paradigms.

${ }^{2}$ Four inflection classes are also postulated by Corbett \& Fraser (1993). In contrast, only three inflection classes are adopted by Halle (1994), Aronoff (1994), and others, who conflate inflection classes I and IV (paradigms $\mathrm{P}_{1}$ and $\mathrm{P}_{4}$ in the present approach) into a single inflection class that contains both masculine and neuter nouns. Such a move then requires additional stipulations for nominative singular and accusative singular contexts. Moreover, we will later see that there are syncretisms in the plural that are shared only by inflection class II and inflection class IV; an explanation for this kind of syncretism will crucially presuppose that inflection classes I and IV are separate. 
The markers of inflection class II are listed in paradigm $\mathrm{P}_{2}$. Most of the nouns belonging to this inflection class are feminine. In addition to the feminine stems, some masculine stems also belong to this class (like mužčin('man')); these stems trigger masculine agreement but inflect according to the pattern in $\mathrm{P}_{2}$. There is no animacy effect (in the accusative or elsewhere) in this paradigm (compare komnat- ('room'), učitel'nic- ('female teacher')). However, there is syncretism: The markers for dative and locative case are identical: $e$. Again, the noun stem may end in a hard ([+back]) or soft ([-back]) consonant (compare komnat- with nedel'- ('week')), which leads to "palatalized" versions of what is clearly the same basic marker in the second case (note that $y$ differs from $i$ only in that the former is [+back], the latter [-back]).

$P_{2}:$ Inflection class II, Sg.: fem, masc

\begin{tabular}{|c|c|c|c|c|}
\hline & \multicolumn{4}{|c|}{ II } \\
\hline & $\begin{array}{l}\text { komnat }_{f} \\
\text { ('room') }\end{array}$ & $\begin{array}{l}\text { učitel'nic } f \\
\text { ('teacher') }\end{array}$ & $\begin{array}{l}\text { nedel' }_{f} \\
\text { ('week') }\end{array}$ & $\begin{array}{l}\text { mužčin }_{m} \\
\text { ('man') }\end{array}$ \\
\hline nom/sg & komnat-a & učitel'nic-a & nedel-ja & mužčin-a \\
\hline acc/sg & komnat-u & učitel'nic-u & nedel-ju & mužčin-u \\
\hline dat/sg & komnat-e & učitel'nic-e & nedel-e & mužčin-e \\
\hline gen/sg & komnat-y & učitel'nic-y & nedel-i & mužčin-y \\
\hline inst/sg & komnat-oj(u) & učitel'nic-ej(u) & nedel-ej(u) & mužčin-oj(u) \\
\hline loc/sg & komnat-e & učitel'nic-e & nedel-e & mužčin-e \\
\hline
\end{tabular}

Consider next the markers of inflection class III in paradigm $\mathrm{P}_{3}$. With only one exception (put' ('way'), which is masculine), all the nouns that inflect according to this class are feminine. Furthermore, all stems end in a soft ([-back]) consonant. As with class II members, there is no animacy effect (compare tetrad'- ('notebook') with myš'- ('mouse')); but there is massive syncretism: Nominative and accusative forms share a null marker $\varnothing$, and dative, genitive, and locative forms have a uniform $i$ as a marker. A few (albeit highly frequent) nouns (doč'- ('daughter'), mat'- ('mother')) exhibit stem alternation; this must be lexically marked, and I will ignore it in what follows.

The markers of inflection class IV are shown in paradigm $\mathrm{P}_{4}$. All nouns that follow this paradigm are neuter. As already noted, this paradigm is similar to paradigm $\mathrm{P}_{1}$, which contains only masculine nouns. The main difference in the singular is that the marker for nominative and accusative case is $o$ throughout in inflection class IV (as before, there is $[ \pm$ back]-governed 
$P_{3}:$ Inflection class III, Sg.: fem

\begin{tabular}{|c|c|c|c|}
\hline & \multicolumn{3}{|c|}{ III } \\
\hline & tetrad' $_{f}$ ('notebook') & $m y \check{s}_{f}$ ('mouse') & doč' ${ }_{f}$ ('daughter') \\
\hline nom $/ \mathrm{sg}$ & tetrad'- $\varnothing$ & myš'- & doč'- $\varnothing$ \\
\hline acc/sg & tetrad'- $\varnothing$ & myš'- & doč'-Ø \\
\hline dat/sg & tetrad-i & myš-i & doč-er-i \\
\hline gen/sg & tetrad-i & myš-i & doč-er-i \\
\hline inst/sg & tetrad'-ju & myš'-ju & doč-er'-ju \\
\hline loc/sg & tetrad-i & myš-i & doč-er-i \\
\hline
\end{tabular}

morpho-phonological variation in this domain; compare pol' ('field')). Further support for the distinction between class I and class IV (see footnote 2) comes from the observation that there is no animacy effect in paradigm $\mathrm{P}_{4}$ (see Corbett \& Fraser (1993)): A neuter noun in this class exhibits nominative/accusative syncretism rather than accusative/genitive syncretism even if it is animate; compare suščestv- ('creature').

$P_{4}:$ Inflection class IV, Sg.: neut

\begin{tabular}{|c|c|c|c|c|}
\hline & \multicolumn{4}{|c|}{ IV } \\
\hline & mest $_{n}$ ('place') & jablok $_{n}$ ('apple') & suščest $_{n}$ ('creature') & pol' $_{n}$ ('field') \\
\hline nom $/ \mathrm{sg}$ & mest-o & jablok-o & suščestv-o & pol-e \\
\hline $\mathrm{acc} / \mathrm{sg}$ & mest-o & jablok-o & suščestv-o & pol-e \\
\hline dat/sg & mest-u & jablok-u & suščestv-u & pol-ju \\
\hline gen/sg & mest-a & jablok-a & suščestv-a & pol-ja \\
\hline inst/sg & mest-om & jablok-om & suščestv-om & pol-em \\
\hline loc/sg & mest-e & jablok-e & suščestv-e & pol-e \\
\hline
\end{tabular}

Most Russian nouns are in one of these four inflection classes. Many of those nouns that do not follow one of the patterns in $\mathrm{P}_{1}-\mathrm{P}_{4}$ are not part of the native vocabulary and do not take any case marker whatsoever; these indeclinables (like kofe ('coffee')) are sometimes viewed as belonging to a separate inflection class. Finally, there are exceptional nouns which are not covered by the system sketched so far because they take unexpected markers, or because they exhibit stem alternation. ${ }^{3}$ Also, a comprehensive account of Russian noun inflection would also have to integrate the issue of variable

\footnotetext{
${ }^{3}$ To name just one case where an unexpected marker occurs: Certain masculine nouns that follow the basic pattern of inflection class I can also have $u$ instead of $a$ as the genitive singular marker in certain syntactic environments, as in $\check{c} a-j u$ vs. $\check{c} a-j a$ ('tea').
} 
vs. invariant stress in inflectional paradigms. Still, I take it that the core system of Russian noun inflection is adequately described by the four inflection classes documented in $\mathrm{P}_{1}-\mathrm{P}_{4}$, and I will now turn to the issue of how the generalizions embodied in $\mathrm{P}_{1}-\mathrm{P}_{4}$ can be derived.

\subsection{Inflection Class Features}

The task at hand is to predict the correct inflection marker for any Russian noun stem and any case specification in the singular; for instance, it must be ensured that the noun stem zavod-takes the marker $u$ in dative singular contexts, and not, say, $e$ or $i$, whereas the noun stem komnat- takes the marker $e$ in dative singular contexts, and not $u$ or $i$. Ideally, one might expect that independently motivated features of the stem suffice for this purpose, and that inflection class features can be dispensed with. Relevant inherent features of stems include gender features and phonological features; and it has indeed been proposed that inflectional markers can always be determined by taking into account only features of this type (see, e.g., Steins (1998) for such an approach to Old English noun inflection, and Wunderlich (1996; this volume) for the outlines of such an approach to Russian noun inflection).

However, closer inspection reveals that resorting to inherent (gender or phonologigcal) features of noun stems is unlikely to yield an adequate system (see Wurzel (1984), Corbett \& Fraser (1993), Fraser \& Corbett (1994), Aronoff (1994), and Halle (1994), among others). Consider first gender features. There is almost a one-to-one correspondence between the gender feature neuter and paradigm $\mathrm{P}_{4}$, i.e., all neuter stems inflect according to this paradigm, and all stems that inflect according to this paradigm are neuter. ${ }^{4}$ However, the correlation breaks down with the features masculine and feminine. Whereas most masculine noun stems follow paradigm $\mathrm{P}_{1}$, there are also some masculine noun stems that follow paradigm $\mathrm{P}_{2}$ (e.g., muščin- ('man')). What is worse, feminine noun stems may either inflect according to paradigm $\mathrm{P}_{2}$, or according to paradigm $\mathrm{P}_{3}$, and they predominate in both classes (the

\footnotetext{
${ }^{4}$ Pejorative diminutives like domišk- ('cottage') and gorodišk- ('little town') might qualify as exceptions because they are masculine but inflect according to inflection class IV in the singular. However, their behaviour in the plural is non-homogeneous (mixing classes I and IV), so that additional lexical specifications are unavoidable anyway with these noun stems, and they might be taken to belong to inflection class I after all (with a lexical specification as taking $o$ in the nominative singulrar).
} 
vast majority of noun stems inflecting according to $\mathrm{P}_{2}$ are feminine, and, with the exception of the isolated noun stem put', all noun stems that follow the pattern in $\mathrm{P}_{3}$ are feminine). Thus, gender features alone do not reliably encode inflection class in Russian. Neither do phonological features of a stem, for obvious reasons. Not even a combination of gender and phonological features will suffice: Masculine noun stems inflecting according to $\mathrm{P}_{1}$ do not differ systematically in any obvious way from masculine noun stems inflecting according to $\mathrm{P}_{2}$ with respect to their phonological properties; and, even though feminine noun stems that obey $\mathrm{P}_{3}$ are all marked [-back] on the last consonant, this combined information is not enough to conclude that a feminine, [-back] noun stem like tetrad'- must follow $\mathrm{P}_{3}$ (and, e.g., take $i$ rather than $e$ in the dative singular) because feminine, [-back] noun stems may also follow $\mathrm{P}_{2}$; compare nedel'-.

Other independently motivated features of noun stems (e.g., semantic features) also fail to correctly predict inflection class membership - and if it looks as though they succeed in this, this is invariably due to the fact that the features in question are not independently motivated after all since they do not designate anything except for inflection class. As a case in point, consider the status of "theme" vowels (and theme consonants). From a diachronic perspective, there is a relation between the phonological nature of the ending of a noun stem and the inflection class that it belongs to, and remnants of this system can still be found in Old Bulgarian, where a partition of inflection classes according to theme vowels and theme consonants is still synchronically motivated to some extent (see Leskien (1955), among others) - e.g., there is a theme consonant $n$ that shows up with most forms in the paradigm of the $n$-stem inflection class, and that is distinct from the respective inflection marker. Thus, in Old Bulgarian, inflection class membership can at least partially be determined by phonological properties of the stem. However, this is certainly not the case anymore in modern Russian. Of course, we can in principle distinguish between, say, $\varnothing$-stems, $a$-stems, $i$-stems, and $o$-stems, corresponding to the four inflectional patterns in $\mathrm{P}_{1}-\mathrm{P}_{4}$. But the only thing that has been accomplished by this is that we now have names for inflection class features: The phonological properties of, e.g., an $a$-stem (viz., exhibiting an /a/ segment) are not manifest on the stem - they exclusively show up on an inflection marker of the paradigm (this point is emphasized in Wurzel (1984, 124)).

The only way out under the assumption that a theme vowel like $a$ exists as 
part of a stem would be to stipulate that there is a null ending in nominative singular contexts, where the theme vowel shows up - thus, the nominative singular marker of a noun in inflection class II would be $\varnothing$ rather than $a$ (e.g., komnata- $\varnothing$ instead of komnat-a); and that there is an obligatory deletion rule in non-nominative singular contexts, where the theme vowel does not show up (e.g., komnata- $u \rightarrow$ komnat- $u$ in accusative singular environments). However, such an analysis lacks independent justification, and arguably comes close to undermining the notion of theme vowel. ${ }^{5}$ All in all, it seems that an approach to Russian noun inflection that relies on theme vowels (and/or theme consonants) cannot make predictions that go beyond those of an approach that relies on arbitrary inflection class features (see Fraser \& Corbett (1994)). ${ }^{6}$ As a general result, I would like to conclude that a recourse to inflection class features is unavoidable in an account of noun inflection in Russian. The question then is what these features look like, and whether they play a role in an analysis of syncretism.

\section{Inflection Class Features as a Source of Syncretism}

\subsection{Syncretism}

Thus far, the focus has been on syncretism within a given paradigm: Depending on the animacy status, the inflection markers for either nominative and accusative $(\varnothing)$, or for genitive and accusative $(a)$, are identical in the singular paradigm $\mathrm{P}_{1}$ of inflection class I; the inflection markers for dative and locative $(e)$ have the same form in the singular paradigm $\mathrm{P}_{2}$ of inflection class II;

\footnotetext{
${ }^{5}$ Incidentally, an analysis along these lines might be implied in Wunderlich (1996)'s sketch of the noun inflection system of Russian, which invokes a "(floating) theme vowel" $a$ to distinguish the two (predominantly) feminine inflection classes without recourse to inflection class features. Also see Wunderlich (this volume).

${ }^{6}$ Note in passing that this does not necessarily imply that there can be no theme vowels in Russian nouns; the claim is merely that inflection class assignment does not proceed via theme vowels. Thus, Halle $(1994,50)$ suggests that there is always an underlying theme vowel between stem and inflection marker in Russian nouns, and that this theme vowel is uniformly an $o$. This theme vowel is assumed to emerge as such in some cases (with the instrumental inflection markers $m$, yielding $o-m$, and $j$, yielding $o-j$ ), to be changed to $e$ or $a$ in others (yielding composite endings like $e-j$ or $a-m$ ), and to be deleted in the majority of cases. Crucially, the theme vowel that Halle (1994) postulates is independent of inflection class assignment. I will not adopt this assumption in what follows, but it is worth noting that it could in principle be reconciled with the overall approach that I will suggest in the following section.
} 
the inflection markers for nominative and accusative $(\varnothing)$, and those for dative, genitive, and locative $(i)$, are indistinguishable in the singular paradigm $\mathrm{P}_{3}$ of inflection class III; and the inflection markers for nominative and accusative (o) are identical in the singular paradigm $\mathrm{P}_{4}$ of inflection class IV. However, this does not exhaust the instances of syncretism in Russian noun inflection. In addition to intra-paradigmatic syncretism, there is trans-paradigmatic syncretism in abundance, and it is by no means confined to common markers shared by inflection classes I and IV (which does not come as a surprise, given that these classes are often viewed as one). Thus, for instance, $\varnothing$ shows up in nominative and accusative contexts of inflection class I and inflection class III; $i$ is a marker shared by inflection class II (in the genitive) and inflection class III (in the dative, genitive, and locative); and the inflection marker $a$ occurs in inflection class I (in the genitive, and in the accusative with animates), in inflection class II (in the nominative), and in inflection class IV (in the genitive). The occurrences of both intra- and trans-paradigmatic syncretism are shown in the simplified meta-paradigm in $\mathrm{P}_{5}$ that presents the gist of the paradigms in $\mathrm{P}_{1}-\mathrm{P}_{4}$.

$P_{5}:$ Syncretism within and across inflection classes

\begin{tabular}{|l||c|c|c|c|}
\hline & I & II & III & IV \\
\hline \hline nom & $\varnothing$ & $\mathrm{a}$ & $\varnothing$ & $\mathrm{o}$ \\
\hline acc & $\varnothing / \mathrm{a}$ & $\mathrm{u}$ & $\varnothing$ & $\mathrm{o}$ \\
\hline dat & $\mathrm{u}$ & $\mathrm{e}$ & $\mathrm{i}$ & $\mathrm{u}$ \\
\hline gen & $\mathrm{a}$ & $\mathrm{i}$ & $\mathrm{i}$ & $\mathrm{a}$ \\
\hline inst & om & oj & ju & om \\
\hline loc & $\mathrm{e}$ & $\mathrm{e}$ & $\mathrm{i}$ & $\mathrm{e}$ \\
\hline
\end{tabular}

A common assumption is that at least some instances of syncretism in inflectional paradigms are not accidental, but systematic in the sense that they should follow from the morphological analysis. I will adhere to this view in what follows; in fact, I will adopt an even stronger assumption, viz., that all instances of syncretism should be considered to be systematic whenever possible. This follows from the much more general strategy in (1), which I assume here as a meta-grammatical principle.

(1) Syncretism Principle:

Identity of form implies identity of function

(in a domain $\Sigma$, and unless there is evidence to the contrary). 
The Syncretism Principle may look quite radical, but I take it to be the null hypothesis, both for a child acquiring a language, and for a linguist investigating it. According to (1), all instances of syncretism should initially be considered systematic within a certain grammatical domain, and can be considered accidental only in the face of strong counter-evidence. ${ }^{7}$ Of course, the question is what the domain $\Sigma$ in (1) should be for our present concerns. I assume that $\Sigma$ includes different cases and inflection classes, but not different numbers; i.e., I will not try to account for instances of syncretism that hold between singular and plural. ${ }^{8}$ This difference between number on the one hand and case and class on the other may ultimately be traced back to whether or not a feature carries semantic information - number features do, whereas class features and case features (at least those of the languages under consideration in this paper, which do not exhibit "semantic cases") do not. ${ }^{9}$

Thus, in line with (1), in what follows my goal will be to develop an analysis that accounts for both intra-paradigmatic and trans-paradigmatic syncretism in Russian noun inflection as much as possible. In doing so, I will rely on three basic assumptions: (i) Cases are decomposed into primitive features. (ii) Inflection class features are also decomposed into primitive features. (iii) The notion of competition plays a role in inflectional morphology, in the form of the Specificity Condition. Whereas assumptions (i) and (iii) are

\footnotetext{
${ }^{7}$ This implies a shift of perspective from standard assumptions, and a change of burden of proof: It must be shown that a given instance of syncretism is non-systematic, not that it is systematic. In line with this, I would like to contend that there is indeed less evidence against the systematicity of syncretism than is sometimes made out (see, e.g., Carstairs (1987), Zwicky (1991), Williams (1994)). For instance, there is a commonplace view according to which only few of the syncretisms in German pronominal inflection are systematic because the morphological syncretisms can often be resolved when larger syntactic units (e.g., the NP) are taken into account; see Wunderlich (1997), Wiese (1996), Eisenberg (2000), and Zifonun (2001), among others. This kind of reasoning is argued to be untenable in Müller (2002; 2003). More generally, it seems that a hasty classification of some syncretism as non-systematic may often indicate little more than the fact that a given morphological analysis cannot account for it in a systematic way.

${ }^{8}$ Also see Baerman, Brown \& Corbett (2002).

${ }^{9}$ The denial of systematicity of "trans-number" syncretism implies that the well-known effect of alternation between nominative singular and genitive plural (see below on the latter) with respect to the occurrence of $\varnothing$ (an inflection class has $\varnothing$ in the genitive plural iff it does not have $\varnothing$ in the nominative singular) must be considered accidental from a synchronic perspective. Incidentally, all systematic accounts of this phenomenon that I am aware of require a significantly more complex approach, e.g., by permitting reference to existing output forms in the determination of markers; see Bailyn \& Nevins (2003) for a recent analysis; also see Wiese (this volume, 353).
} 
adopted in analyses of noun inflection in Russian (and other inflecting languages), assumption (ii) is not. It is assumption (ii) that will turn out to make it possible to account for trans-paradigmatic syncretism in the same way that intra-paradigmatic syncretism is accounted for via assumption (i), and it is the absence of assumption (ii) in previous analyses that has so far made it impossible to account for trans-paradigmatic syncretism in a non-stipulative way (see section 3.5 below).

\subsection{Analysis}

\subsubsection{Background Assumptions}

I will make the following assumptions about the nature of inflectional morphology and its place in grammar. The lexicon is a mere list of exceptions without rules or constraints. The morphological component follows the lexicon but precedes the syntactic component - the inputs of morphology are members of the list of lexical items of a given language, and the outputs of morphology are fully inflected word forms that then enter syntactic derivations (or lexical arrays, in the system of Chomsky (2000; 2001)). Noun stems and inflection markers are listed in the lexicon; thus, inflection markers have morpheme status. I assume that the features that noun stems bear in the lexicon include (inherent) categorial and gender features, but not (variable) case or number features; these latter features are added when the noun stem enters the morphological component. In contrast, inflection markers bear case (and other morpho-syntactic) features in the lexicon. A noun stem and an inflection marker can be combined in the morphological component if the two items do not have contradictory features or features values (only the latter case will be relevant in what follows). ${ }^{10}$

\footnotetext{
${ }^{10}$ Stump (2001) introduces two general dichotomies for inflectional theories: An inflectional theory may be lexical (inflection markers are - possibly abstract - lexical items) or inferential (inflection markers are not lexical items); and it may be incremental (inflection markers add information) or realizational (inflection markers do not add information). According to this classification, the approach to be developed below qualifies as lexical (since inflection markers have morpheme status) and realizational (since inflection markers do not contribute any information that is not present on the noun stem already), just like distributed morphology (see Halle \& Marantz (1993), Halle (1994), and Harley \& Noyer (1999) for an overview); however, it crucially differs from distributed morphology in not postulating empty Q-morphemes (or f-morphemes) that are then realized by spell-out rules which produce in-
} 
Let me now address in turn the status of case features, inflection class features, and the Specificity Condition.

\subsubsection{Decomposition of Case Features}

The idea to decompose the cases of Russian into combinations of more primitive features goes back to Jakobson (1962a) (which first appeared in 1936) and Jakobson (1962b). Jakobson's original system relies on three semantically-based features and has been subject to various extensions and modifications throughout the last decades (see Neidle (1988), Franks (1995), and Gvozdanović (1991), among others). In his account of pronominal inflection in German, Bierwisch (1967) assumes a syntactic rather than semantic basis for the primitive features that characterize the four German cases. Bierwisch's system is adopted in Wiese (1999), and extended so as to cover the six cases of Latin in Wiese (2001). Following Bierwisch and Wiese, I will assume as basic the three binary features $[ \pm$ subj(ect)], $[ \pm$ gov(erned)], [ \pm obl(ique $)]$. The six Russian cases can then be decomposed as in (2). ${ }^{11}$

\footnotetext{
flection markers of the type in $\mathrm{P}_{5}$. That said, I would like to emphasize that the gist of the approach to syncretism in Russian noun inflection to be developed below could be transferred without much ado into many existing inflectional theories, be they lexical-realizational (like distributed morphology), lexical-incremental (like the lexical theories of Lieber (1992), Wunderlich (1996; 1997), among others), or inferential-realizational (like, in particular, the wordand-paradigm approaches developed by Anderson (1992), Corbett \& Fraser (1993), Aronoff (1994), and Stump (2001), and others cited in these works). The only relevant properties that an inflectional theory must have are (i) that it permits feature decomposition, and (ii) that it acknowledges a notion of competition - as a matter of fact, a version of the present proposal is developed within a distributed morphology approach in Müller (2004b). The specific version of a lexical-incremental approach adopted here will become relevant only in section 4 .

${ }^{11}$ As it stands, the combinations [+subj, +gov,-obl], [-subj,-gov,-obl] do not correspond to any case in Russian, an inevitable consequence of cross-classifying three binary features. Following the reasoning in Jakobson und much subsequent literature, one might try to close the gap by postulating alternative feature combinations for two of the cases (usually, genitive and locative are then treated this way), or by assuming abstract cases that are not morphologically manifest (e.g., an abstract vocative comes to mind for the feature specification [-subj,-gov,-obl]); see Wiese (2001) on Latin. However, I will refrain from pursuing these options here.
} 


\section{(2) Decomposition of cases in Russian:}

$$
\begin{aligned}
& \text { nominative: [+subj,-gov,-obl] } \\
& \text { accusative: [-subj, }+ \text { gov, }- \text { obl }] \\
& \text { dative: } \quad[- \text { subj },+ \text { gov, },+ \text { obl }] \\
& \text { genitive: } \quad[+\mathrm{subj},+ \text { gov },+ \text { obl }] \\
& \text { instrumental: [+subj,-gov,+obl] } \\
& \text { locative: [-subj,-gov,+obl] }
\end{aligned}
$$

A few remarks are in order here concerning the syntactic nature of the three features and their role in determining the cases of Russian. First, the [+subj] cases nominative, genitive, and instrumental all typically show up on arguments that are merged last with a predicate (NP-internally with the genitive, in passive constructions with the instrumental); i.e., [+subj] basically encodes a notion of subject as it is employed in a categorial grammar tradition (see, e.g., Zifonun et al. (1997)). Second, the [+gov] cases accusative, dative, and genitive are the protoypical cases for objects governed by V. Finally, the [+obl] cases dative, genitive, instrumental, and locative differ from the non-oblique cases nominative and accusative in that the latter (but not the former) typically encode the core arguments of $\mathrm{V}$, and in that only the latter qualify as structural in the sense of Chomsky (1981). ${ }^{12}$

The fundamental insight behind case decomposition is that natural classes of cases can thus be formed, and such a natural class of cases can then be what an inflection marker is characterized by. In other words, an inflection marker does not necessarily have a full $[ \pm \mathrm{subj}, \pm \mathrm{obj}, \pm \mathrm{obl}]$ specification; it may be underspecified with respect to (decomposed) case features, in which case it designates a natural class of cases rather than a single case. For instance, as we will see in a moment, the inflection marker $i$ is characterized not by a full set of case features in the present approach, but by an underspecified set of case features [+obl], which makes it compatible with the natural class of oblique cases (dative, genitive, instrumental, and locative) and, thereby, contributes to an explanation of (intra-paradigmatic as well as transparadigmatic) $i$ syncretism in the oblique domain. Similarly, the inflection marker $u$ is assumed to be underspecified as [-subj, + gov], which plays an

\footnotetext{
${ }^{12}$ Needless to say, the morphological case specifications based on these features only reflect primary syntactic functions, and may be at variance with other syntactic functions. Underlying this is the assumption that it is unlikely that a simple, homogeneous specification (be it syntactic or semantic) can be found for all cases, in all their occurrences (see Isačenko (1975, 81)); but see, e.g., Bailyn (2003) for a recent attempt concerning the Russian genitive.
} 
important role in deriving the instances of (trans-paradigmatic) $u$ syncretism in the natural class of cases so defined (viz., accuative and dative).

\subsubsection{Decomposition of Inflection Class Features}

In the same way that intra-paradigmatic syncretism has been shown to be accountable for by decomposing case features, I would like to suggest that trans-paradigmatic syncretism can fruitfully be addressed by decomposing inflection class features; i.e., I take it that the existence of trans-paradigmatic syncretism suggests that inflection classes can form natural classes, just like cases do. For concreteness, suppose that inflection classes are decomposed into more primitives features as in (3). ${ }^{13}$

\footnotetext{
${ }^{13}$ There are predecessors of this idea. First, Corbett \& Fraser (1993) suggest a common additional inflection class feature 0 that is present with inflection class features I and IV. This "meta-inflection class feature" contributes to an account of trans-paradigmatic syncretisms affecting inflection classes I and IV. However, this approach does not extend to other instances of trans-paradigmatic syncretism; moreover, the existence of a natural class comprising inflection classes I and IV is simply stipulated this way (by introducing an additional feature 0 ), and not derived (by feature decomposition). Second, there is an approach to trans-paradigmatic syncretism along gender/number categorizations with pronominal inflection in German developed in Wiese (1996; 1999) (and adopted in one way or another in Eisenberg (2000), Zifonun (2001), and Müller (2002)) that relies on a decomposition of the (combined) categories gender and plural; this proposal and the present one converge if one is willing to make the (admittedly somewhat unusual) assumption that different gender/number categorizations in German are in fact different inflection classes. On this view, inflection class features, while without inherent meaning as such, may in some languages be interpreted along the gender/number distinction. Furthermore, there are three approaches that I only got to know after the first draft of this paper was completed, and that are quite similar in spirit to the present proposal: The first of these is Oltra Massuet's (1999) analysis of verbal inflection in Catalan, which relies on a decomposition of inflection class features that looks very much like the one adopted here. Next, Halle $(1992,38)$ employs the primitive, decomposed features [ \pm marginal], $[ \pm$ marked] (in addition to the "standard" class features A, B) in his analysis of Latvian noun inflection, essentially so as to account for instances of trans-paradigmatic syncretism. Finally, Nesset (1994, 229ff.) develops an analysis of Russian noun inflection that uses [ \pm nom-end] and [a/igen-end] as primitive class features, again in order to account for instances of trans-paradigmatic syncretism. The analysis has a limited scope (involving only a few of the attested cases of transparadigmatic syncretism, and no cases of intra-paradigmatic syncretism), and stays somewhat informal (e.g., theoretical issues arising with underspecification and competition of inflection markers are not explored - more generally, no attempt is made to account for the whole system of noun inflection in a systematic way); nevertheless, it is clearly guided by the same underlying idea. Note also that class feature decomposition is suggested in Alexiadou \& Müller (2004) for noun inflection in Greek and German, and in Müller (2004a) for noun inflection
} 
(3) Decomposition of inflection classes in Russian:

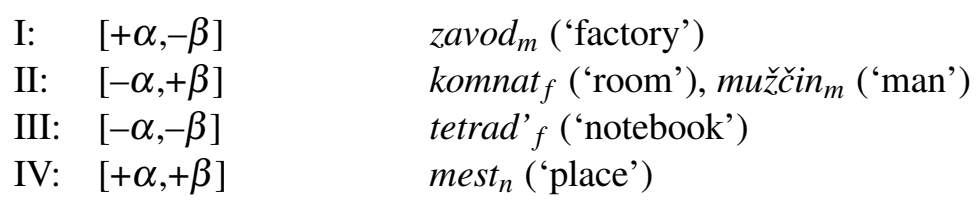

Here, $\alpha$ and $\beta$ are purely formal features that do not stand for anything else; but this state of affairs is not particularly worrisome when we take into account that the situation is not different with standard inflection class features like [I], [II], [III], and [IV] (if anything, the situation has improved because there are now two binary features instead of four privative features). The decomposition in (3) predicts (not surprisingly) that inflection classes I and IV form a natural class (characterized by $[+\alpha]$ ); but it also implies that natural classes are formed by (the predominantly feminine) inflection classes II and III (characterized by $[-\alpha]$ ), by inflection classes II and IV (characterized by $[+\beta]$ ), and by inflection classes I and III (characterized by $[-\beta]$ ). As a result, the system now permits inflection markers to be underspecified with respect to inflection class; for instance, the inflection marker $i$ has only the inflection class feature $[-\alpha]$, which makes it suitable for noun stems with either inflection class II $([-\alpha,+\beta])$ or inflection class III $([-\alpha,-\beta])$ specifications, but not for other noun stems. However, classes I and II do not form a natural class of inflection classes, and the same goes for classes III and IV. Consequently, no feature specification of an inflection marker can refer to either of these groups of inflection classes, and we expect that there is no instance of trans-paradigmatic syncretism that applies exclusively to classes I and II, or to classes III and IV. This prediction is borne out.

Based on these assumptions about primitive inflection class features, we can now look at the lexical entries for the singular inflection markers that attach to Russian nouns. Underspecified class information is underlined in the feature specifications of markers in the list in (4).

in Icelandic. For attempts to establish natural classes of noun inflection classes in Russian without invoking feature decomposition, see McCreight \& Chvany (1991) and Wiese (this volume). 
(4) Inflection markers for nouns in Russian:

\begin{tabular}{|c|c|}
\hline 1. /oj/ & $\{[+\mathrm{N}],[-\alpha,+\beta],[+\mathrm{subj},-\mathrm{gov},+\mathrm{obl}]$ \\
\hline /ju/ & $\{[+\mathrm{N}],[-\alpha,-\beta],[+\mathrm{subj},-\mathrm{gov},+\mathrm{obl}]\}$ \\
\hline /om/ & $\{[+\mathrm{N}], \underline{[+\alpha]},[+\mathrm{subj},-\mathrm{gov},+\mathrm{obl}]\}$ \\
\hline /e/ & $\{[+\mathrm{N}], \overline{[-\alpha,+\beta],[-\mathrm{subj},+\mathrm{obl}]\}}$ \\
\hline /e/ & $\{[+\mathrm{N}],[+\alpha],[-\mathrm{subj},-\mathrm{gov},+\mathrm{obl}]\}$ \\
\hline$/ \mathrm{o} /$ & $\{[+\mathrm{N}], \overline{[+\alpha},+\beta],[-\mathrm{obl}]\}$ \\
\hline$/ \mathrm{O} /$ & $\{[+\mathrm{N}], \underline{[-\beta],[-\mathrm{obl}]\}}$ \\
\hline /i/ & $\{[+\mathrm{N}], \overline{[-\alpha]},[+o b l]\}$ \\
\hline$/ \mathrm{u} /$ & $\{[+\mathrm{N}], \overline{[-\mathrm{subj}},+$ gov $]\}$ \\
\hline$/ \mathrm{a} /$ & $\{[+\mathrm{N}]\}$ \\
\hline
\end{tabular}

These inflection markers, as lexical items, have the status of underlying representations; they are abstract elements that may undergo further phonological or morphological changes (hence, the / / notation which will be adopted from now on). Thus, I assume that the actual inflection marker realizations om and $\mathrm{em}$ both go back to underlying /om/; there is a morpho-phonological rule that realizes /om/ as em after a soft ([-back]) consonant. Similarly, underlying /oj/ is realized as $e j$ after a [-back] consonant, and as oj otherwise. Furthermore, I postulate that there is a morpho-phonological rule that that realizes underlying /i/ as $y$ after a hard ([+back]) consonant (and as $i$ otherwise). In addition to these morpho-phonological rules, and perhaps somewhat more controversially, I assume that a general phonological rule is responsible for the realization of the underlying inflection marker $/ \mathrm{O} /$, which has extensively been argued to have inflection marker status by Halle (1994). /O/ is an abstract vowel (a "yer") that Halle assumes to otherwise bear the same features as /o/; there is a general rule that deletes abstract vowels unless they immediately precede a syllable with another abstract vowel (which, of course, they never do if they are inflection markers at the end of a word). Thus, $/ \mathrm{O} /$ replaces the null marker $\varnothing$ assumed in the above paradigms. ${ }^{14}$ One advantage of adopting $/ \mathrm{O} /$ as an inflection marker is that it makes it possible to avoid positing null morphemes as inflection markers that are specified by case and inflection class features (this is a domain where inferential approaches to inflection may

\footnotetext{
14/O/ surfaces in word forms like /ókOn $\Theta / \rightarrow$ okon ('window', genitive plural), where the inflection marker $/ \mathrm{O} /$ is deleted (see section 3.4 below), whereas the stem vowel $/ \mathrm{O} /$ survives (and is realized as $o$ ); compare the nominative singular form /ok $\Theta$ nó/ $\rightarrow o k n-o$, where $/ \mathrm{O} /$ in the stem is deleted because it does not precede an abstract vowel itself. See Kenstowicz \& Rubach (1987) (and literature cited there) for more on yers in Slavic.
} 
have an initial advantage over lexical approaches). A second advantage is that $/ \mathrm{O} /$, unlike a null morpheme, can be shown to fit very well into a system of form/function correlations that can be derived naturally from (4); see section 3.3 below.

Note now that (4) comes close to a maximally successful execution of the program embodied in (1): Except for /e/, which has two lexical entries, there are no homophonous inflection markers in the singular. There is only one feature set for a given inflection marker; this feature set is underspecified in most cases. Thus, if (4) can be shown to correctly predict the paradigms in $\mathrm{P}_{1}-\mathrm{P}_{4}$, we can conclude that syncretism in Russian noun inflection in the singular has been accounted for (almost, given /e/) in its entirety. However, due to the very fact that most of the inflection markers are underspecified with respect to case and inflection class features, the system developed so far is not yet constrained enough. It overgenerates in the sense that, in many cases, there are two or more inflection markers that would be compatible with a given fully specified feature set on a noun stem. To see this, suppose that a noun stem like komnat- is taken from the lexicon, and enriched by dative and singular features, so that its specification includes the set $\{[+\mathrm{N}],[-\alpha,+\beta],[-\mathrm{subj},+$ gov,,$+\mathrm{obl}],[-\mathrm{pl}]\}$. The task now is to find an inflection marker with a compatible feature specification; and the problem is that, as things stand, we do not find one but four, viz.: /e/ in (4-4) (or /e/4, as I will write from now on), $/ \mathrm{i} / 8, / \mathrm{u} / 9$, and $/ \mathrm{a} / 10$. These markers compete in $\{[-\alpha,+\beta],[-$ subj,+ gov,+ obl $]\}$ contexts. The situation is similar with nearly all other contexts characterized by combinations of fully specified inflection class features and case features that show up on noun stems. Thus, what is needed is a general principle that decides the competition of inflection markers and selects a winner among the competing markers that is the only grammatical form in any given context. A principle that has this effect is the Specificity Condition. ${ }^{15}$

\footnotetext{
${ }^{15}$ One might try to avoid all instances of competition among inflection markers by revising the lexical entries for these markers in such a way that only one marker can be appropriate for any given full specification of case and inflection class features in the first place. However, such a move would necessarily conflict with (1), and would thus make a systematic account of syncretism impossible. To see this, consider a simple example. The inflection marker $/ \mathrm{i} / 8$ shows up in the dative, genitive, and locative of inflection class III, and with the genitive only in inflection class II. Clearly, there is no way how the four feature specifications that characterize these four environments can form a natural class; the minimal set of specifictions that includes these four will invariably also have to include the specifications for dative and locative of inflection class II, which have different markers. Thus, in a nutshell, competition
} 


\subsubsection{The Specificity Condition}

For present purposes, the Specificity Condition can be formulated as in (5):

\section{(5) Specificity Condition:}

If two competing forms $\mathrm{F}_{i}, \mathrm{~F}_{j}$ satisfy all local constraints on operations, and $\mathrm{F}_{i}$ is more specific than $\mathrm{F}_{j}$, then $\mathrm{F}_{i}$ is to be preferred over $\mathrm{F}_{j}$.

Applying this general condition to the case at hand, the competing forms are different inflection markers that can be attached to a given noun stem. An operation in the sense of (5) is the concatenation of a noun stem and its inflection marker in the singular. The relevant local constraint is that stem and marker do not have incompatible values for case, inflection class, and number features (this ensures that highly specific inflection markers that are incompatible with a given stem cannot be chosen as the optimal (according to (5)) marker for this stem). This analysis presupposes the existence of two different types of constraints in grammar, viz., local constraints and translocal constraints (typical translocal constraints in syntax are transderivational constraints). To find out whether a local constraint is satisfied by some form, it suffices to consider only the properties of this form; in contrast, to find out whether a translocal constraint is satisfied by some form, the properties of competing forms also have to be taken into account. The Specificity Condition is a translocal constraint. ${ }^{16}$ The question then is how specificity can be defined. A simple assumption would be that an inflection marker $\mathrm{F}_{i}$ is more specific than another marker $\mathrm{F}_{j}$ if $\mathrm{F}_{i}$ has more morpho-syntactic (case and

of markers (and a strategy to resolve it) is necessary to explain syncretism in cases where underspecification alone does not suffice.

${ }^{16}$ The effects of the Specificity Condition on nominal inflection markers can also be derived in what is arguably a somewhat less insightful way by extrinsic ordering; this is most common for those morphological approaches that rely on rules; see, e.g., Bierwisch (1967), Wurzel (1984), Wurzel (1998), and Halle (1994). Similarly, optimality theory (see Prince \& Smolensky (1993)) can account for all specificity effects, in phonology and morphology (see Prince (1996)) as well as in syntax (see Müller (2000)); this is so for the simple reason that optimality theory has a much more variable concept of competition, and is a much more powerful (and hence, less constrained) competition-based approach than one that only relies on the Specificity Condition. Finally, versions of the Specificity Condition are variously known as the Blocking Principle, the Subset Principle, the Elsewhere Condition, the Proper Inclusion Principle, and so on. Analyses that employ this kind of constraint include Kiparsky (1973), Kiparsky (1982), Aronoff (1976), DiSciullo \& Williams (1987), Williams (1994), Williams (1997), and Fanselow (1991). Also compare the literature on specificity given in the text below. 
inflection class) features (alternatively, if $\mathrm{F}_{j}$ 's feature specification is a proper subset of that of the feature specification of $\mathrm{F}_{i}$ ); on this view, the maximally underspecified inflection marker $/ \mathrm{a} / 10$ will emerge as least specific, and fully specified forms like $/ \mathrm{oj} / 1, / \mathrm{ju} / 2$, and $/ \mathrm{om} / 3$ as most specific. However, it has often been argued that such a notion of specificity is not yet fine-grained enough, and must be supplemented by recourse to a general hierarchy of features; see Lumsden (1992), Noyer (1997), Wiese (1999), Gunkel (2003), and Zifonun (2003), among others. In line with this, I would like to propose that inflection class features are always more specific than (i.e., outrank) case features; and I will adopt the following notion of specificity of an inflection marker. ${ }^{17,18}$

(6) Specificity of inflection markers:

An inflection marker $F_{i}$ is more specific than an inflection marker $F_{j}$ iff there is a class of features $\mathbb{C}$ such that (i) and (ii) hold.

(i) $F_{i}$ bears more features belonging to $\mathbb{C}$ than $F_{j}$ does.

(ii) There is no higher-ranked class of features $\mathbb{C}^{\prime}$ such that $F_{i}$ and $F_{j}$ have a different number of features in $\mathbb{F}^{\prime}$.

Paradigm $\mathrm{P}_{6}$ shows how the Specificity Condition interacts with the assumptions about underspecification of inflection markers (with respect to case and inflection class features) made above to predict the system of inflection marking of Russian singular nouns. ${ }^{19}$

The most underspecified inflection marker $/ \mathrm{a} /{ }_{10}$ is a default marker that would in principle fit everywhere; but given the Specificity Condition, it can only survive in the few contexts where there is no alternative, more specific inflection marker that is compatible with the morpho-syntactic feature specification of the noun stem. Thus, $/ \mathrm{a} / 10$ emerges as the unmarked inflection marker for Russian singular nouns, and this way, the analysis provides a uni-

\footnotetext{
${ }^{17}$ A theory-internal reason for invoking the hierarchy of features in the definition of specificity is the distribution of $/ u / 9$, which has two case features but no inflection class features and must qualify as less specific than the markers $/ 0 / 6, / O / 7$, and $/ \mathrm{i} / 8$. The latter are restricted to certain inflection classes but have fewer case specifications, and may thus (in the case of $/ \mathrm{O} / 7$ and $/ \mathrm{i} / 8$ ) end up with an identical number of morpho-syntactic case and inflection class specifications overall.

${ }^{18}$ Note that the concept of specificity in (6) is conceptually similar to the notion of optimality in optimality-theoretic approaches; see Prince \& Smolensky (1993).

${ }^{19}$ The markers chosen by the Specificity Condition are in bold face; compatible, but less specific markers are shown for each combination of case/inflection class in a second line in parentheses.
} 
$P_{6}:$ The interaction of inflection markers in the singular in Russian

\begin{tabular}{|c|c|c|c|c|}
\hline & $\mathrm{I}:[+\alpha,-\beta]$ & II: $[-\alpha,+\beta]$ & III: $[-\alpha,-\beta]$ & IV: $[+\alpha,+\beta]$ \\
\hline $\begin{array}{l}\text { nom: } \\
{[+ \text { subj,-gov,-obl] }}\end{array}$ & $\begin{array}{l}/ \mathbf{O} / 7 \\
(/ \mathrm{a} / 10)\end{array}$ & $/ \mathbf{a} / 10$ & $\begin{array}{l}/ \mathbf{O} / 7 \\
(/ \mathrm{a} / 10)\end{array}$ & $\begin{array}{c}/ 0 / 6 \\
(/ / \mathrm{a} / 10)\end{array}$ \\
\hline $\begin{array}{l}\text { acc: } \\
{[- \text { subj,+gov,-obl] }}\end{array}$ & $\begin{array}{c}/ \mathbf{O} / 7 \\
\left(/ \mathrm{u} / 9, / \mathrm{a} /{ }_{10}\right) \\
\end{array}$ & $\begin{array}{c}/ \mathbf{u} / 9 \\
(/ \mathrm{a} / 10)\end{array}$ & $\begin{array}{c}/ \mathbf{O} / 7 \\
\left(/ \mathrm{u} / 9, / \mathrm{a} /{ }_{10}\right)\end{array}$ & $\begin{array}{c}1 / \mathbf{o} / 6 \\
\left(/ \mathrm{u} / 9, / \mathrm{a} /{ }_{10}\right)\end{array}$ \\
\hline $\begin{array}{l}\text { dat: } \\
{[- \text { subj,+gov,+obl] }}\end{array}$ & $\begin{array}{c}/ \mathbf{u} / 9 \\
(/ \mathrm{a} / 10)\end{array}$ & $\begin{array}{c}/ \mathbf{e} / 4 \\
\left(/ \mathrm{i} / 8, / \mathrm{u} / 9, / \mathrm{a} /{ }_{10}\right)\end{array}$ & $\begin{array}{c}/ \mathbf{i} / 8 \\
\left(/ \mathrm{u} / 9, / \mathrm{a} /{ }_{10}\right)\end{array}$ & $\begin{array}{c}/ \mathbf{u} / 9 \\
(/ \mathrm{a} / 10)\end{array}$ \\
\hline $\begin{array}{l}\text { gen: } \\
{[+ \text { subj,+gov, }+ \text { obl] }}\end{array}$ & $/ \mathbf{a} / 10$ & $\begin{array}{c}/ \mathbf{i} / 8 \\
\left(/ \mathrm{a} /{ }_{10}\right)\end{array}$ & $\begin{array}{c}/ \mathbf{i} / 8 \\
\left(/ \mathrm{a} /{ }_{10}\right)\end{array}$ & $/ \mathbf{a} / 10$ \\
\hline $\begin{array}{l}\text { inst: } \\
{[+ \text { subj,-gov,+obl] }}\end{array}$ & $\begin{array}{l}/ 0 m / 3 \\
(/ a / 10)\end{array}$ & $\begin{array}{c}/ \mathbf{o j} / 1 \\
(/ \mathrm{i} / 8, / \mathrm{a} / 10)\end{array}$ & $\begin{array}{c}/ \mathbf{j u} / 2 \\
\left(/ \mathrm{i} / 8, / \mathrm{a} /{ }_{10}\right)\end{array}$ & $\begin{array}{l}\mathbf{l o m} / 3 \\
(/ \mathrm{a} / 10)\end{array}$ \\
\hline $\begin{array}{l}\text { loc: } \\
{[- \text { subj,-gov,+obl] }}\end{array}$ & $\begin{array}{c}/ e / 5 \\
(/ a / 10)\end{array}$ & $\begin{array}{c}/ \mathbf{e} / 4 \\
(/ \mathrm{i} / 8, / \mathrm{a} / 10)\end{array}$ & $\begin{array}{c}/ \mathbf{i} / 8 \\
(/ \mathrm{a} / 10)\end{array}$ & $\begin{array}{c}/ \mathbf{e} / 5 \\
(/ \mathrm{a} / 10)\end{array}$ \\
\hline
\end{tabular}

form account of $/ \mathrm{a} / 10$ syncretism even though the morpho-syntactic feature specifications of its occurrence contexts (nominative of inflection class II, genitive of inflection classes I and IV) are radically different.

The next least specified inflection marker is $/ \mathrm{u} / 9$, which emerges as the general accusative/dative inflection marker, without any inflection class restriction. However, due to the Specificity Condition, $/ \mathrm{u} / 9$ actually shows up only in few of the accusative/dative cells of paradigm $\mathrm{P}_{6}$, where more specific markers are not available (still, $/ \mathrm{u} / 9$ blocks less specific $/ a / 10$ here): $/ \mathrm{u} / 9$ is selected in the accusative of inflection class II, and in the dative of inflection classes I and IV.

The markers $/ \mathrm{i} / 8, / \mathrm{O} / 7$, and $/ \mathrm{o} / 6$ are more specific than $/ \mathrm{u} /{ }_{10}$ but still qualify as substantially underspecified forms: $/ \mathrm{i} / 8$ is the general obliqueness marker for the $[-\alpha]$ inflection classes II and III; $/ \mathrm{O} / 7$ is the general non-obliqueness marker for the $[-\beta]$ inflection classes I and III; and $/ 0 / 6$ is the general nonobliqueness marker for inflection class IV. However, the uniform, homogeneous distribution that one might a priori expect under these classifications is severely disturbed by the existence of more specific forms. For instance, $/ \mathrm{i} / 8$ is blocked by various more specific markers in four of the eight paradigm cells in which it would be compatible with the morpho-syntactic feature specification of the noun stem. In two of these cases, the blocking marker is /e/ 4 .

In contrast to what is the case with the other inflection markers, the syncretism with /e/ is not fully resolved in the present analysis. As it stands, there are two lexical entries for $/ \mathrm{e} / \mathrm{in}(4): / \mathrm{e} / 4$ and $/ \mathrm{e} / 5$. This correlates with the fact 
that both /e/ markers are quite specific (both /e/ 4 and /e/5 are fully specified except for one feature). ${ }^{20}$

Finally, the instrumental case marker $/ \mathrm{om} / 3$ is minimally underspecified with respect to inflection class features so as to be compatible with inflection classes I and IV; and the instrumental case markers $/ \mathrm{oj} /{ }_{1}$, $/ \mathrm{ju} / 2$ for inflection classes II and III are not underspecified at all. The reason behind this is not that underspecification would be impossible here (it would not be); it is that these markers simply do not participate in competition, and fail to exhibit syncretism.

Thus, most of the intra- and transparadigmatic instances of syncretism in Russian noun inflection are accounted for in a systematic way. Still, there is one important exception: The animacy effect with inflection class I (animates in this class exhibit accusative/genitive syncretism) is not yet systematically accounted for; in fact, so far it is not accounted for at all. It is indeed hard to see how a minor modification of feature specifications of inflection markers could derive the accusative/genitive syncretism with animates of inflection

\footnotetext{
${ }^{20}$ See section 3.3 below for more on the special status of /e/. Also note that a conceivable alternative (which had in fact been adopted in an earlier version of the present paper) would be to view $/ \mathrm{e} / 4$ as a fully specified inflection marker for dative contexts of inflection class II. This would imply that the occurrence of /e/ in the locative of inflection class II is accounted for differently. The obvious solution would then seem to be that $/ \mathrm{e} / 5$ is treated as a locative marker for inflection classes I, II, and IV (rather than only I and IV, as in the present approach). However, I, II, and IV do not form a natural class of inflection classes under present assumptions. In view of this, would might assume a feature specification of $/ \mathrm{e} / 5$ that replaces $[+\alpha]$ with $[\neg(-\alpha,-\beta)]$. On this view, /e/ 5 differs from the other markers in (4) in that it involves reference to the complement of a natural class, viz. $[\neg \mathrm{III})]$ : /e/ $/ 5$ then is compatible with all inflection classes except for inflection class III. Given deMorgan's laws, this can be reformulated as a disjunction: $[\neg(-\alpha,-\beta)]=[+\alpha] \vee[+\beta]$. There is some disagreement about whether or not disjunctions should be avoided in feature specifications of the type at hand (see, e.g., Blevins (1995) vs. Wunderlich (1997)). It seems to me that the use of low-level disjunctions of the type at hand (which could always be undone by introducing an additional feature) is in principle harmless and arguably independently motivated (cf. the analysis of pronominal inflection in German in Müller (2002)) - the basic idea here is that complements of natural classes can also function as natural classes, as has been suggested by Zwicky (1970). However, if one chooses not to draw this conclusion but still wants to maintain a different treatment of locative and dative /e/ in class II, the disjunction implicit in $[\neg(-\alpha,-\beta)]$ might have to be resolved in favour of two separate feature specifications $([+\alpha]$ and $[+\beta])$. This would result in three entries for /e/, which does not strike me as very convincing. That said, I take the question of whether /e/ in the locative of class II is to be treated on a par with /e/ in the dative of class II, or with /e/ in the locative of classes I and IV, to be open; but at least for the purposes of this paper, I will continue to adopt the specification given in the main text, which does not involve reference to the complement of a natural class.
} 
class I. A first problem is that the inflection marker that triggers the syncretism is $/ \mathrm{a} / 10$, which we have seen to be radically underspecified. Hence, $/ \mathrm{a} / 10$ can only show up if there is no other suitable inflection marker; but there are already two other inflection markers that are compatible with accusative singular specifications in inflection class $\mathrm{I}(/ \mathrm{O} / 7$ and $/ \mathrm{u} / 9)$. A second problem is that, as things stand, accusative and genitive do not form a natural class in the present proposal ([-subj,+gov,-obl] vs. [+subj,+gov, + obl] $]$ ). None of these problems strikes me as insurmountable. ${ }^{21}$ Still, I will not pursue the strategy of accounting for this syncretism in terms of decomposition and specificity here. ${ }^{22}$ The main reason for not attempting this is that exactly the same pattern shows up with the plural (see below), and this is unlikely to be accidental (as it would be expected to be under an approach via decomposition and specificity). For the sake of concreteness, I would like to suggest that this syncretism is handled by a rule of referral (see Zwicky (1985)), i.e., a rule that explicitly states (and does not derive) the fact that the marker for a given morpho-syntactic context is identical to the marker of some other morpho-syntactic context; such a rule may thus override the results of the core system based on decomposition and specificity. The following rule of referral is based on similar rules in Corbett \& Fraser $(1993,135)$ and Stump (2001, 229); the suspension of the decomposition- and specificity-based outcome by this rule is reflected in the formulation of the rule (where " $\mathrm{I}_{\{\ldots\}}$ " stands for

\footnotetext{
${ }^{21}$ For instance, one might devise a system in which the markers $/ O / 7$ and $/ u / 9$ are in fact incompatible with an accusative specification of a noun that belongs to inflection class I and contains the feature [+animate]. It is also worth noting that there is a surplus case characterization $[+$ subj, + gov, - obl] that might be considered a second version of the genitive, and that does form a natural class with the accusative ([+gov,-obl]); recall footnote 11 .

${ }^{22}$ Such a strategy is adopted, in one way or another, in Neidle (1988), Franks (1995), Gunkel (2003) (for Polish), and Wunderlich (this volume). In doing so, Neidle, Franks, and Gunkel rely on the idea that [+animate] and [-animate] noun stems give rise to different paradigms (i.e., inflection classes). Wunderlich's solution is based on the assumption that accusative and genitive form a natural class (defined by the case feature [+hr]), which accounts for instances of A/G syncretism. Absence of syncretism is then derived either by postulating more specific markers for genitive and/or accusative (as with class II and class III noun stems); or (in the case of class I and class IV noun stems) by invoking what arguably amounts to a version of the impoverishment operation of distributed morphology: A special (violable, but highranked) constraint penalizes the realization of the case feature [+hr] in accusative contexts of inanimate (or neuter) nouns, and thus brings about a "retreat to the general case", as Halle \& Marantz (1993) put it - i.e., a retreat to the less specific marker that is also used in nominative contexts. See pp. 381-385; and Trommer (2001) for a general approach to impoverishment in terms of optimality-theoretic constraints.
} 
"the inflection marker determined by the Specificity Condition for context $\{\ldots\}$ ", and " $\rightarrow$ " stands for "is replaced by"); essentially, (7) triggers differential object marking (see Aissen (2003) and literature cited there), which overrides the basic morphological outcome (Comrie (1978)). ${ }^{23}$

(7) A rule of referral for accusative/genitive syncretism in the singular: $\mathrm{I}_{\{[+\alpha,-\gamma],[-\mathrm{subj},+\mathrm{gov},-\mathrm{obl}]\}} \rightarrow \mathrm{I}_{\{[+\alpha,-\gamma],[+\mathrm{subj},+\mathrm{gov},+ \text { obl }]\}} /[+$ animate $]$

\subsection{On Form and Function}

At first sight, the system of inflection markers in (4) may seem arbitrary. However, closer inspection reveals that there is an interesting correlation of marker form and marker function. The inflection markers in (4) are basically ordered according to a property of their function: From top to bottom, specificity decreases. However, this order goes hand in hand with an independent order that concerns a property of the inflection markers' form: From top to bottom, the rank of a marker on the Sonority Hierarchy (see Hankamer \& Aissen (1974)) increases. Thus, the consonantal markers are at one end of the hierarchy, the most sonorous marker $/ \mathrm{a} / 10$ is at the other end, and the other vocalic markers show up in between, with $/ \mathrm{u} / 9$ being more sonorours than $/ \mathrm{i} / 8, / \mathrm{O} / 7$, and $/ \mathrm{o} / 6$, and these being more sonorous than $/ \mathrm{e} / 4 / 5 .{ }^{24}$ Thus, the hi-

\footnotetext{
${ }^{23}$ Both Corbett \& Fraser (1993) and Stump (2001) maximize the use of rules of referral in the account of syncretism, and also extend it to intra-paradigmatic syncretism. See section 3.5 below.

${ }^{24}$ Three remarks: one on /e/, one on /O/, and one on /u/. First, there is an independent reason why /e/ should differ from vocalic markers like /i/ and /o/. The marker /e/ is in fact usually (except after consonants like $/ \mathrm{c} /, / \check{s} /, / \check{z} /$ ) realized as $j e$, which makes this marker quasiconsonantal. Thus, the high degree of specificity of /e/'s function (and the fact that the /e/ syncretism is not fully resolvable under present assumptions) directly corresponds to the fact that /e/ is less sonorous than purely vocalic markers.

Second, we are now in a position to formulate the second of the arguments for assuming the null ending in the nominative and accusative of inflection classes I and III to be an abstract vowel $/ \mathrm{O} / 7$ (that has otherwise the same features as $/ 0 / 6$ and is deleted in word-final position), and not a genuine null morpheme: The marker in question has a similar function (degree of specificity) as /o/6. Hence, given that optimal grammar design maximizes form/function correspondence, we expect it to have a similar form as well. This is the case if the marker is $/ \mathrm{O} / 7$, but not if the marker is a null morpheme $/ \varnothing /$ devoid of phonological features.

Third, the classification of $/ \mathrm{u} / 9$ as being more sonorous than $/ 0 / 6$ is not compatible with evidence from external sandhi in Greek (see Matthews (1974, 113-114)), which presupposes the order $/ \mathrm{i} />/ \mathrm{e} />/ \mathrm{u} />/ \mathrm{o} />/ \mathrm{a} /$ of increasing sonority; with evidence from binomial
} 
erarchy in (8) reflects both the morphological function and the phonological form of the markers. ${ }^{25}$

(8) $/ \mathrm{oj} /, \mathrm{lju} /, / \mathrm{om} />/ \mathrm{e} />/ \mathrm{o} /, / \mathrm{O} /, \mathrm{li} />/ \mathrm{u} />/ \mathrm{a} /$

This correlation can be taken to suggest that a notion like optimal grammar design plays a role in inflectional morphology, and that, in addition to the Syncretism Principle in (1), fusional systems of inflection might adhere to a second, related meta-grammatical Iconicity Principle that differs from the Syncretism Principle only in that the concept of "identity" is replaced with the concept of "similarity", and that may plausibly be assumed to guide (and simplify) acquisition of inflectional systems in the same way:

(9) Iconicity Principle:

Similarity of form implies similarity of function

(in a domain $\Sigma$, and unless there is evidence to the contrary).

\subsection{Plural}

Thus far, I have been exclusively concerned with singular paradigms. The plural paradigms of Russian noun inflection are indeed much less interesting than the singular paradigms from the point of view of syncretism. Still, mainly for the sake of completeness (but also to provide a further argument for decomposing inflection class features), I will now address plural paradigms.

formation in German (see Ross (1980, 42), Müller (1997, 33)), which presupposes the order $/ \mathrm{i} />/ \mathrm{u} />/ \mathrm{e} />/ \mathrm{O} / \mathrm{l} / \mathrm{a} /$; and with evidence from sonority-driven reduction in languages like Bulgarian and Catalan (see Crosswhite (2000), and also Kenstowicz (1994)). This may indicate some language-particular variability, or minor imperfections of some of the systems involved here.

${ }^{25}$ An even more systematic correlation of marker form and (underspecified) marker function has been discovered for the system of pronominal inflection in German in Wiese (1996; 1999), on which the present discussion draws (as does the sonority-based approach to German pronominal inflection in Müller (2002)). As concerns the Russian system of noun inflection, it has not gone unnoticed either in the literature that there might be a correlation of form and function. Thus, Shapiro $(1969,14)$ and Plank $(1979,143)$ correlate a Jakobsonian hierarchy of cases $\mathrm{H}_{c}\left(\right.$ nom $>$ inst $>$ gen $_{2}>\operatorname{loc}_{2}>$ acc $>$ dat $>$ gen $\left._{1}>\operatorname{loc}_{1}\right)$ and a Sonority Hierarchy $\mathrm{H}_{s}$ ( $\mathrm{a}>\mathrm{o}, \mathrm{e}, \mathrm{u}, \mathrm{i}>\mathrm{v}, \mathrm{j}, \mathrm{m}>\mathrm{x}$ ); Plank states the following generalization: "The higher-ranked a case is in $\left[\mathrm{H}_{c}\right]$, the more sonorous is the set of phonological segments used for its expression." I would argue that replacing this hierarchy of cases with a hierarchy of specifications of decomposed case and inflection class features permits a more articulate (and verifiable) account that nevertheless preserves Plank's and Shapiro's basic insight. 
The distribution of markers in the plural across the four inflection classes is shown in paradigm $\mathrm{P}_{7}$.

\section{$P_{7}:$ Inflection classes I-IV in the plural}

\begin{tabular}{|c|c|c|c|c|}
\hline & $\begin{array}{c}\text { I } \\
\text { zavod }_{m} \\
\text { ('factory') }\end{array}$ & $\begin{array}{c}\text { II } \\
\text { komnat }_{f} \\
\text { ('room') }\end{array}$ & $\begin{array}{c}\text { III } \\
\text { tetrad' } \\
\text { ('notebook') }\end{array}$ & $\begin{array}{c}\text { IV } \\
\text { mest } \\
\text { ('place') }\end{array}$ \\
\hline nom/pl & zavod-y & komnat-y & tetrad-i & mest-a \\
\hline acc/pl & zavod-y & komnat-y & tetrad-i & mest-a \\
\hline dat/pl & zavod-am & komnat-am & tetrad-jam & mest-am \\
\hline gen $/ \mathrm{pl}$ & zavod-ov & komnat- $\varnothing$ & tetrad-ej & mest- $\varnothing$ \\
\hline inst/pl & zavod-ami & komnat-ami & tetrad-jami & mest-ami \\
\hline loc/pl & zavod-ax & komnat-ax & tetrad-jax & mest-ax \\
\hline
\end{tabular}

(10) is a (slightly simplified) list of lexical entries for plural inflection markers in Russian.

(10) Plural inflection markers for nouns in Russian:

$$
\begin{array}{lll}
\text { 1. } & \text { /ax/ } & \{[+\mathrm{N}],[+\mathrm{pl}],[-\mathrm{subj},- \text { gov },+ \text { obl }]\} \\
\text { 2. } & \text { /ami/ } & \{[+\mathrm{N}],[+\mathrm{pl}],[+\mathrm{subj},- \text {-gov, }+ \text { obl }]\} \\
\text { 3. } & \text { /am/ } & \{[+\mathrm{N}],[+\mathrm{pl}],[-\mathrm{subj},+ \text { gov, }+ \text { obl }]\} \\
\text { 4. } & \text { /ov/ } & \{[+\mathrm{N}],[+\mathrm{pl}],[-\beta],[+\mathrm{subj},+ \text { gov, }+ \text { obl }]\} \\
\text { 5. } & \text { /O/ } & \{[+\mathrm{N}],[+\mathrm{pl}],[+\beta],[+\mathrm{subj},+ \text { gov, }+ \text { obl }]\} \\
\text { 6. } & \text { /i/ } & \{[+\mathrm{N}],[+\mathrm{pl}],[\neg(+\alpha,+\beta)],[-\mathrm{obl}]\} \\
\text { 7. } & \text { /a/ } & \{[+\mathrm{N}],[+\mathrm{pl}],[-\mathrm{obl}]\}
\end{array}
$$

Let us consider the locative, instrumental, and dative markers $/ \mathrm{ax} / 1, / \mathrm{ami} / 2$, and $/ a m / 3$ first. These markers are invariant across inflection classes (and genders), and generally seem to behave very differently from the singular markers discussed above - they resemble truly agglutinative markers. Even though underspecification of case features is technically possible in these cases, there is no evidence for doing this; and despite the fact that there is no reason for specifying inflection class features for these markers, we can assume that they are maximally specific, and can never be blocked in favour of other markers by the Specificity Condition. (As a matter of fact, it is questionable whether they should be subsumed under a decomposition/specificity-based approach in the first place, given that there is no interaction with other markers.) Next, there are two genitive markers in the plural: $/ \mathrm{O} / 5$ (i.e., the null ending) shows up with inflection classes II and IV, and /ov/4 occurs with inflection classes 


\section{Gereon Müller}

I and III (/ov/4 is realized as $e j$ rather than as $o v$ after a [-back] consonant as the result of a morpho-phonological rule; see Halle (1994, 53ff.)). This instance of trans-paradigmatic syncretism provides further evidence for decomposing inflection class features (the inflection classes II and IV form a natural class characterized by the feature $[+\beta]$, the inflection classes I and III form a natural class characterized by the feature $[-\beta]$ ); but (even though it would again be technically possible) there is no need to underspecify case features and invoke the Specificity Condition with these two markers. At this point, a general conclusion concerning the decomposition of inflection class features can be drawn: For each natural class of inflection classes, there is in fact a feature specification of an inflection marker that refers to it: $[+\alpha](\mathrm{I}$, IV) is referred to by the singular markers $/ \mathrm{om} / 3$ and $/ \mathrm{e} / 5 ;[-\alpha]$ (II, III) by the singular marker $/ \mathrm{i} / 8 ;[+\beta]$ (II, IV) by the plural marker $/ O / 5$; and $[-\beta]$ (I, III) by the singular marker $/ O / 7$ and by the plural marker $/ o v / 4$.

There are only two instances of intra-paradigmatic syncretism in the plural: Nominative and accusative are identical in the presence of the feature [-animate], and accusative and genitive are identical in the presence of the feature [+animate]. Thus, the pattern of inflection class I shows up more generally in the plural. Accordingly, the analysis given here will be of the same type: Nominative/accusative syncretism is viewed as the unmarked case predicted by decomposition and specificity, and accusative/genitive syncretism with animates is stated by a rule of referral. Turning to nominative/accusative syncretism with inanimate nouns first, this is the only case where it makes sense to underspecify case features on inflection markers in the plural. For concreteness, I suggest that the only case information that $/ \mathrm{i} / 6$ and $/ \mathrm{a} / 7$ bear as plural markers is the feature [-obl]; and that $/ \mathrm{a} / 7$ is not specified with respect to inflection class whereas $/ \mathrm{i} / 6$ is characterized as being compatible with all inflection classes except class IV. Consequently, $/ \mathrm{i} / 6$ is more specific than $/ \mathrm{a} / 7$ in the nominative and accusative of inflection classes I, II, and III, and this is why $/ \mathrm{a} / 7$ is blocked here via the Specificity Condition. Thus, $/ \mathrm{a} / 7$ is the unmarked inflection marker in the plural as it it the unmarked inflection marker in the singular. ${ }^{26}$

\footnotetext{
${ }^{26}$ Thus, the feature specification of the plural marker $/ \mathrm{i} / 6$ refers to the complement of a natural class; recall footnote 20 . A priori, /i/ could also be considered the default marker; this would avoid a reference to complements of natural classes. However, treating /a/ as the default marker is not only motivated by a considerations related to a parallel behaviour of singular and plural, and to iconicity: There is also a tendency to replace /i/ with /a/ as the [-obl] plural marker in certain lexical domains in class I (see, e.g., Isačenko (1975, 97-99);
} 
The plural markers in $(10)$ are marked [+pl], whereas the singular markers in (4) are not specified for number features. Suppose that number features are inherently more specific than inflection class features (which in turn are more specific than case features, see above). Then, the Specificity Condition will ensure that plural markers always block singular markers in any given plural context; conversely, plural markers (marked [+pl]) are always incompatible with fully specified singular noun stems (marked [-pl]), so they can never block the less specific singular markers in singular contexts. ${ }^{27}$ The resulting plural paradigm is shown in $\mathrm{P}_{8}$.

\section{$P_{8}$ : Minimal interaction of inflection markers in the plural}

\begin{tabular}{|c|c|c|c|c|}
\hline & $\mathrm{I}:[+\alpha,-\beta]$ & II: $[-\alpha,+\beta$ & III: $[-\alpha,-\beta]$ & IV: $[+\alpha,+\beta]$ \\
\hline $\begin{array}{l}\text { nom: } \\
{[+ \text { subj,-gov,-obl] }}\end{array}$ & $\begin{array}{c}/ \mathbf{i} / 6 \\
(/ a / 7)\end{array}$ & $\begin{array}{c}\mathbf{i} / 6 \\
(/ \mathrm{a} / 7)\end{array}$ & $\begin{array}{c}\mathbf{i} / 6 \\
(/ \mathrm{a} / 7)\end{array}$ & $/ \mathbf{a} / 7$ \\
\hline $\begin{array}{l}\text { acc: } \\
{[- \text { subj, +gov,-obl] }}\end{array}$ & $\begin{array}{c}/ \mathrm{i} / 6 \\
(/ \mathrm{a} / 7)\end{array}$ & $\begin{array}{l}/ \mathrm{i} / 6 \\
(/ \mathrm{a} / 7)\end{array}$ & $\begin{array}{c}/ \mathrm{i} / 6 \\
(/ \mathrm{a} / 7)\end{array}$ & $/ \mathbf{a} / 7$ \\
\hline $\begin{array}{l}\text { dat: } \\
{[- \text { subj, +gov, }+ \text { obl }]}\end{array}$ & $/ \mathrm{am} / 3$ & $/ \mathrm{am} / 3$ & $/ \mathrm{am} / 3$ & $/ \mathbf{a m} / 3$ \\
\hline $\begin{array}{l}\text { gen: } \\
{[+ \text { subj,+gov,+obl] }}\end{array}$ & $/ \mathrm{ov} / 4$ & $/ 0 / 5$ & $/$ ov $/ 4$ & $/ 0 / 5$ \\
\hline $\begin{array}{l}\text { inst: } \\
{[+ \text { subj,-gov,+obl] }}\end{array}$ & $/ \mathbf{a m i} / 2$ & $/ \mathbf{a m i} / 2$ & $/ \mathbf{a m i} / 2$ & $/ \mathbf{a m i} / 2$ \\
\hline $\begin{array}{l}\text { loc: } \\
{[- \text { subj,-gov, }+ \text { obl] }}\end{array}$ & $/ \mathbf{a x} / 1$ & $/ \mathbf{a x} / 1$ & $/ \mathbf{a x} / 1$ & $/ \mathbf{a x} / 1$ \\
\hline
\end{tabular}

Finally, a rule of referral needs to be formulated that covers the accusative/genitive syncretism with animate nouns in the plural; the rule is a version of the rule of referral for the same syncretism with inflection class I members in the singular (see (7)), with inflection class features replaced by a number feature. Thus, the two rules can be viewed as different instantiations of a single general rule scheme.

this productive strategy might be taken to indicate a default status of /a/. - On the other hand, /i/ replaces /a/ in neuter contexts in various Russian dialects; see Cubberley $(2002,325)$.

${ }^{27}$ Thus, no attempt is made here to account for instances of singular/plural syncretism. Even the two /a/ markers must be distinguished - the "singular" marker /a/ (i.e., the one unspecified for number) is blocked by $/ \mathrm{O} /$ in nominative/accusative plural contexts of inflection class IV, and only the presence of the more specific plural marker /a/ (marked $[+\mathrm{pl}])$ can ensure the correct outcome. 
(11) A rule of referral for accusative/genitive syncretism in the plural: $\mathrm{I}_{\{[+\mathrm{pl}],[-\mathrm{subj},+ \text { gov },-\mathrm{ob}]]\}} \rightarrow \mathrm{I}_{\{[+\mathrm{pl}],[+ \text { subj, }+ \text { gov },+ \text { obl }]\}} /[+$ animate $]$

\subsection{Interim Conclusion}

To sum up so far, the decomposition of case and inflection class features into more primitive features, and the reliance on the Specificity Condition (a translocal constraint that picks out the most specific inflection marker from a set of inflection markers that are compatible with a noun stem), make it possible to account for many instances of both intra-paradigmatic and transparadigmatic syncretism in Russian noun inflection. As far as I am aware, a systematic analysis that derives (rather than simply states) this latter type of syncretism has so far been outstanding, even though there are many analyses of syncretism in Russian noun inflection. A brief overview may illustrate this.

The original system of case feature decomposition into three semantically based primitives $([ \pm$ mar(ginal) $],[ \pm$ quant(ified) $]$, and $[ \pm \operatorname{dir}($ ectional $)])$ in Jakobson (1962b) is modified and extended to systems based on four primitive features by Neidle (1988) (who adopts the features $[ \pm$ locational], [ \pm quantifying], $[ \pm$ directional], and $[ \pm$ partial $]$ ) and Franks (1995) (who suggests the features $[ \pm$ oblique], $[ \pm$ marginal], $[ \pm$ nonascriptive $]$, and $[ \pm$ phrasal] $)$. Both approaches have considerable success in accounting for intra-paradigmatic syncretism. However, these analyses significantly overgenerate cases (a cross-classification of four binary features yields sixteen possible cases). More importantly, trans-paradigmatic syncretism cannot be accounted for because inflection classes are taken as basic and do not form natural classes. Wunderlich (1996; this volume), and Gunkel (2003) (for Polish) suggest analyses that rely on case feature decomposition and the Specificity Condition. The use of this latter constraint makes it possible to account for intra-paradigmatic syncretism in a simple way; but again, an account of trans-paradigmatic syncretism is out of reach.

In contrast to all of these approaches, the analysis in Halle (1994) captures instances of intra-paradigmatic as well as trans-paradigmatic syncretism. However, it does so only by having disjunctive application contexts in spellout rules for an abstract Q-morpheme that represents the inflection marker for nouns. Thus, it seems fair to say that syncretism is stated but not derived 
in this approach. ${ }^{28}$ The situation is similar with the approaches in Corbett \& Fraser (1993) and Stump (2001). These analyses manage to account for various kinds of intra-paradigmatic and, more importantly from the present perspective, trans-paradigmatic syncretism, but since they almost exclusively rely on rules of referral to achieve this, instances of syncretism are stated but not derived. ${ }^{29}$

The specific lexical-realizational framework of inflectional morphology that I have adopted throughout has not been crucial so far. Given some obvious adjustments, the gist of the above analysis can also be formulated in other approaches (including word-and-paradigm approaches, distributed morphology approaches, and classical lexical-incremental approaches), as long as they permit a reference to natural classes created by feature decomposition and incorporate a translocal constraint like the Specificity Condition. This translatability disappears when I discuss the role of inflection class features in the following section. The argument to be given there supports an approach that is both lexical (the inflection marker is a lexical item) and realizational (all morpho-syntactic features that are needed in syntax are present on the noun stem already).

\section{Inflection Class Features as Triggers of Inflection}

\subsection{Features in Morphology and Syntax}

The features that play a role in inflectional morphology are generally considered morpho-syntactic, in the sense that they are visible in both morphology and syntax and mediate between the two components. Against this background, inflection class features (whether decomposed or not) are peculiar

\footnotetext{
${ }^{28}$ For instance, Halle $(1994,51)$ accounts for all three occurrences of /a/ as a noun inflection marker in Russian (genitive singular of inflection classes I and IV, nominative singular of inflection class II, nominative/accusative plural of inflection class IV) by a single rule. This rule does not identify these distinct contexts as a natural class, though - rather, the three environments are simply listed as possible application contexts: Q $\rightarrow / \mathrm{a} /$ in the environments $\{[+\mathrm{N}],[$ ClassI(IV)],[Sg-Gen $]\},\{[+\mathrm{N}],[$ ClassII],[Sg-Nom $]\}$, and $\{[+\mathrm{N}],[\mathrm{Class}(\mathrm{IV})],[\mathrm{Pl}-\mathrm{Nom}]\}$ (under certain conditions, in the last case).

${ }^{29}$ For instance, Corbett \& Fraser $(1993,137)$ account for the /i/ syncretism in inflection classes II and III by assuming that /i/ is basic with a genitive singular specification of inflection class II, and rules of referral ensure that the genitive, dative, and locative singular markers of inflection class III are identical to it.
} 
because they do not seem to be visible in syntax. Thus, whereas syntactic operations refer to case, gender, and number features, they completely ignore inflection class features. To see this, suppose, counterfactually, that inflection class features were relevant in syntax. Then, we might expect there to be verbs that select inflection class features such that, e.g., only inflection class III members were available as objects of these verbs in Russian; or we might expect subject-verb agreement with respect to inflection class (i.e., a designated morphological reflex of the subject's inflection class on the verb). Things like these do not seem to occur. ${ }^{30}$ So, I would like to conclude that inflection class features are of no use in syntax; they are not interpretable in this component. Assuming a general Legibility Condition (see Chomsky (1986; 2000; 2001)) according to which all material present at a given level of grammar must be interpretable at that level, the presence of inflection class features on nouns in the syntax is a problem.

Given the assumptions of section 3, this problem is much more general, though: Case, number, and gender features are (or, at least, can be) present on both a noun stem and its inflection marker. A well-established generalization for inflecting languages is that the head of a word (with respect to some feature) in syntax is typically the rightmost element (that bears this feature); compare the notion of "relativized head" in DiSciullo \& Williams (1987). If both a noun stem and an inflection marker have case features, the inflection marker is predicted to be the relavized head of the word with respect to case in Russian, for the simple reason that inflection is suffixal in this language. However, this leads to a dilemma, given that inflection markers can be underspecified with respect to case features: Underspecified case features of an inflection marker should at best be visible in syntax, and at worst also block the visibility of fully specified case features on the noun stem. ${ }^{31}$ But if the underspecified case information of an inflection marker is visible in syntax, predictions are made which are not borne out. For instance, we would expect that there are verbs that select underspecified cases like [-subj,+gov], which is clearly not the case. ${ }^{32}$ Independently of these empirical problems, I take

\footnotetext{
${ }^{30}$ Bernstein (1993) argues that inflection class is visible as a functional head in syntax; but see Alexiadou (this volume) for a refutation of this assumption.

${ }^{31}$ It should be noted that this problem does not arise in inferential-realizational approaches in which inflection markers do not bear features as such.

${ }^{32}$ The present system would predict an inflection class-invariant marker $/ \mathrm{u} /$ on all nouns selected by such a verb.
} 
the redundant proliferation of morpho-syntactic features on noun stem and inflection markers to be conceptually unwarranted.

Taking these two problems together, I conclude that all inflection class features, and all morpho-syntactic features of an inflection marker, are uninterpretable in syntax and not visible in this component. These features are underlined in (12) for two nouns, tetradi ('notebook', dative singular, inflection class III) and komnatu ('room', accusative singular, inflection class II).

(12) a. $/$ tetrad' $/\{[+\mathrm{N}],[-$ anim $],[-\mathrm{pl}],[\underline{[-\alpha,-\gamma]},[-\mathrm{subj},+$ gov,+ obl $]\}$

$-/ \mathrm{i} /\{\underline{\{+\mathrm{N}],[-\alpha],[+\mathrm{obl}]\}}\}$

b. $\quad /$ komnat $/\{[+\mathrm{N}],[-$ anim $],[-\mathrm{pl}],[+\alpha,+\gamma],[-\mathrm{subj},+$ gov,,$-\mathrm{obl}]\}$ $-/ \mathrm{u} /\{\underline{\underline{[+\mathrm{N}],[- \text { subj, }, \text { gov }]}\}}$

Thus, we face the following situation: First, there are features that are necessary in morphology but uninterpretable in syntax; this looks like an imperfection (from the point of view of optimal grammar design). Second, the existence of inflection class-based noun inflection as such already looks like an imperfection - it is "uneconomical and dysfunctional", as Plank (2002) puts it. Interestingly, the co-occurrence of these two imperfections is strongly reminiscent of a situation independently arising in minimalist syntax.

\subsection{Features in Syntax and Logical Form}

Recent versions of the minimalist program (see Chomsky (1995; 2000; 2001)) recognize two fundamental operations in syntax. First, the operation Merge puts together two constituents $\alpha, \beta$. Merge applies freely, but the succesful cases are typically restricted to contexts where there is a selectional relation between $\alpha$ and $\beta$. Second, the operation Move re-merges some subconstituent $\alpha$ of a larger constituent $\beta$ (which has undergone Merge earlier in the derivation) with $\beta$. Simplifying a bit, Move is subject to the restriction that there are identical features on the head of the target (the probe) and on the head of the moved item (the goal) which enter an abstract Agree relation, and, crucially, that there are semantically uninterpretable features on both the probe and the goal, i.e., features that cannot be interpreted in the component of logical form (LF) that follows the syntactic component. Chomsky assumes that LF does not tolerate syntactic features that it cannot interpret; hence, these features have to be deleted in syntax. Generalizing this assumption, we 
obtain the following restriction on feature interpretability, forced by the Legibility Condition:

(13) Feature interpretability:

Features that are uninterpretable at level $\mathrm{L}_{i}$ must be deleted at level $\mathrm{L}_{i-1}$.

Furthermore, Chomsky postulates that the operation Move, which can only apply in the presence of LF-uninterpretable features on the probe, deletes all these features on the probe and the goal, under Agree. Features that are uninterpretable at LF include case features of nouns (but not, e.g., category, gender, number, person and animacy features of nouns) and gender, number, and person features on verbs. Chomsky notes that the existence of LFuninterpretable features looks like an imperfection of grammar design. The same, so he argues, goes for the existence of the operation Move (the "displacement property" of natural languages), which, e.g., removes argument NPs from the domain of verbs that they are arguments of. ${ }^{33}$

\subsection{Inflection in Morphology is like Movement in Syntax}

In view of this evident convergence of morphological inflection and syntactic movement, I think the hypothesis is worth pursuing that inflection (of the type considered in this article, i.e., by fusional, portmanteau markers) has the same status in morphology as movement in syntax: In both cases, the operation is triggered by features that are not interpretable in the next component, and as a result all uninterpretable features are deleted on the two items that participate in the operation. More specifically, I would like to suggest that the noun stem acts as the probe of an inflection operation, triggering Agree with an inflection marker as the goal. Thus, it must be a syntactically uninterpretable feature on the noun stem that triggers the operation; and the only candidate for this is an inflection class feature. Having triggered the inflection operation (in Russian, the suffixation of the noun stem by the inflection marker), the inflection class feature and the morpho-syntactic features of the inflection marker are deleted. Consequently, the inflected nouns that the morphological component delivers to the syntax do not look as in (12), but as in (14):

(14) a. $/$ tetrad' $/_{\{[+\mathrm{N}],[- \text { anim }],[-\mathrm{pl}],[- \text { subj, }+ \text { gov },+ \text { ob }]\}}$ $-/ \mathrm{i} /$

\footnotetext{
${ }^{33}$ See, however, Chomsky (2002) for a different view.
} 
b. $/$ komnat $/\{[+\mathrm{N}],[-$ anim $],[-\mathrm{pl}],[-$ subj,,+ gov,- obl $]\}$ $-/ \mathrm{u} /$

This approach offers a straightforward account of indeclinable noun stems like kofe ('coffee'). One does not have to make special assumptions for this case (like the stipulation that these noun stems belong to an additional inflection class, as it is assumed in Corbett \& Fraser (1993)). The only assumption that is needed is that these noun stems do not have an inflection class feature: If there is no such feature on the noun stem, no inflection operation will be triggered because there is no need to get rid of uninterpretable features by applying inflection. As a result, the noun stem enters the syntax in its bare form.

The analogy of morphology and syntax could be extended even further. E.g., one might argue that morphological operations like derivation and agglutinative inflection are similar to Merge operations in syntax, in the sense that the operation typically goes hand in hand with a selection relation (or can easily be conceived of as doing so). Furthermore, the Specificity Condition that has played an essential role in the analysis of inflection above can arguably be reinterpreted as a subcase of the constraint Maximize Matching Effects that Chomsky $(2001,15)$ proposes for syntax. ${ }^{34}$ However, for reasons of space and coherence, I will not pursue these matters here ${ }^{35}$ neither will I pursue the many questions that the present approach raises. ${ }^{36}$

I would like to conclude with two general remarks. First, the above reasoning supports the organization of grammar that I have adopted throughout this paper: Morphology precedes syntax (so features that play a role in morphology but are uninterpretable in syntax can be deleted before this level is reached), and syntax precedes LF. The main hypothesis in this context is that

\footnotetext{
${ }^{34}$ This constraint demands the deletion of as many uninterpretable features by an operation as is possible. Note that the more specific an inflection marker is, the more uninterpretable features will be deleted by applying the inflection operation.

${ }^{35}$ See Alexiadou \& Müller (2004) for further elaboration, and for a more general discussion of the issues in this section.

${ }^{36}$ To name just one open question: The approach sketched in this section predicts that all kinds of (fusional) inflection are brought about by inflection class features. That is, even in those cases where invoking, say, gender features seems to suffice to determine the appropriate inflection marker for a given noun stem, the present approach will have to postulate inflection class features (that, in the simplest case, may co-vary with (and be parasitic on) the gender features) because gender features of nouns stems, being interpretable in syntax, cannot force inflection with a portmanteau marker.
} 
inflection class features are uninterpretable in syntax and must be deleted by an inflection operation before the syntactic component; and I would like to contend that to the extent that this hypothesis is tenable (and plausible under minimalist assumptions), it argues against a late insertion (i.e., postsyntactic) approach to inflectional morphology (as it is standardly assumed in distributed morphology): At the point where a late insertion approach needs an inflection class feature, the feature has long been deleted. ${ }^{37}$

Second, in discussing the two properties identified as basic imperfections in syntax - (i) uninterpretability of syntactic features at LF, and (ii) displacement -, Chomsky suggests that (i) might not be an imperfection after all because it is the device that makes (ii) possible; and (ii) might not be an imperfection upon closer inspection because there is an independent, functional motivation for displacement based on topic/focus structure and the like (see Chomsky $(2000 ; 2001))$. The same reasoning can be applied to the case at hand. There are two imperfections: (iii) uninterpretability of morphological inflection class features in syntax, and (iv) inflection by fusional markers. As argued above, (iii) is the only device that makes (iv) possible (Plank (2002, 4) speculates that inflection class features "can ... be made sense of as the (regrettable, but inevitable) byproduct of something other really intended"), so it may not be an imperfection after all; and (iv) may perhaps not be an imperfection either, given that inflection via fusional markers looks like a good compromise between explicitness (permitting a simple detection of an NP's grammatical function in syntax) and economy (inflection via agglutinative markers needs more lexical items and creates more complex words).

\title{
References
}

\author{
Aissen, Judith \\ 2003 Differential Object Marking: Iconicity vs. Economy. Natural Language and \\ Linguistic Theory 21, 435-483. \\ Alexiadou, Artemis \\ this volume Inflectional Class, Gender, and DP Internal Structure.
}

\footnotetext{
${ }^{37}$ It seems that the only way out in a late insertion approach would be to invoke a dissociation operation that inserts inflection class features post-syntactically (see Embick (1998) for the concept of dissociation). However, dissociation is at variance with the Inclusiveness Condition (see, e.g., Chomsky (2001)) and, more generally, does not seem to be a sufficiently restricted operation as it stands.
} 
Alexiadou, Artemis \& Gereon Müller

2004 Class Features as Probes. Ms., Universität Stuttgart and IDS Mannheim. Anderson, Stephen

1992 A-Morphous Morphology. Cambridge: Cambridge University Press.

Aronoff, Mark

$1976 \quad$ Word Formation in Generative Grammar. Cambridge, Mass: MIT Press.

1994 Morphology by Itself. Cambridge, Mass: MIT Press.

Baerman, Matthew, Dunstan Brown \& Greville Corbett

2002 Case Syncretism in and out of Indo-European. In Mary Andronis et al. (eds.), The Main Session. Papers from the 37th Meeting of the Chicago Linguistic Society, 15-28. Chicago.

Bailyn, John Frederick

2003 Genitive Case is (Always) Quantificational. Ms., SUNY at Stony Brook.

Bailyn, John Frederick \& Andrew Nevins

2003 The Form of Russian Genitive Plurals. Ms., SUNY at Stony Brook and MIT.

Bernstein, Judy

1993 Topics in the Syntax of Nominal Structure across Romance. Doctoral dissertation, CUNY.

Bierwisch, Manfred

1967 Syntactic Features in Morphology: General Problems of So-Called Pronominal Inflection in German. In To Honour Roman Jakobson, 239-270. The Hague/Paris: Mouton.

Blevins, James

1995 Syncretism and Paradigmatic Opposition, Linguistics and Philosophy 18, 113152.

Bobaljik, Jonathan

2002 Syncretism without Paradigms: Remarks on Williams 1981, 1994. In Geert Booij \& Jaap van Marle (eds.), Yearbook of Morphology 2001, 53-85. Dordrecht: Kluwer.

Carstairs, Andrew

1987 Allomorphy in Inflection. London: Croom Helm.

Carstairs-McCarthy, Andrew

1998 Paradigm Structure: Inflectional Paradigms and Morphological Classes. In A. Spencer \& A. Zwicky (eds.), Handbook of Morphology, 322-334. Oxford: Blackwell.

Chomsky, Noam

1981 Lectures on Government and Binding. Dordrecht: Foris.

1986 Knowledge of Language. New York: Praeger.

1995 The Minimalist Program. Cambridge, Mass: MIT Press.

2000 Minimalist Inquiries: The Framework. In R. Martin, D. Michaels \& J. Uriagereka (eds.), Step by Step, 89-155. MIT Press, Cambridge, Mass.

2001 Derivation by Phase. In M. Kenstowicz (ed.), Ken Hale. A Life in Language, 1-52. Cambridge, Mass.: MIT Press.

2002 Beyond Explanatory Adequacy. Ms., MIT, Cambridge, Mass. 
Comrie, Bernard

1978 Morphological Classification of Cases in the Slavonic Languages, The Slavonic and East European Review 56, 177-191.

Corbett, Greville \& Norman Fraser

1993 Network Morphology: A DATR Account of Russian Nominal Inflection, Journal of Linguistics 29, 113-142.

Crosswhite, Katherine

2000 Sonority-Driven Reduction . Ms. University of Rochester. To appear in Proceedings of BLS 26.

Cubberley, Paul

2002 Russian. A Linguistic Introduction, 313-331. (Chapter "Dialects".) Cambridge: Cambridge University Press.

DiSciullo, Anna-Maria \& Edwin Williams

1987 On the Definition of Word. Cambridge, Mass.: MIT Press.

Eisenberg, Peter

$2000 \quad$ Grundriß der deutschen Grammatik. Band 1: Das Wort. Stuttgart: Metzler.

Embick, David

1998 Voice Systems and the Syntax/Morphology Interface. In H. Harley (ed.), Papers from the UPenn/MIT Roundtable on Argument Structure and Aspect (MITWPL 32), 41-72 Cambridge, Mass.

Fanselow, Gisbert

1991 Minimale Syntax. Habilitation thesis, Universität Passau.

Franks, Steven

1995 Parameters of Slavic Morphosyntax. New York, Oxford: Oxford University Press.

Fraser, Norman \& Greville Corbett

1994 Gender, Animacy, and Declensional Class Assignment: A Unified Account for Russian. In G. Booij \& J. van Marle (eds.), Yearbook of Morphology 1994, 123-150. Dordrecht: Kluwer.

Gunkel, Lutz

2003 Syncretism and Case Underspecification in Polish Noun Paradigms. In P. Banski \& A. Przepiórkowski (eds.), Generative Linguistics in Poland: Morphosyntactic Investigations. (Proceedings of the GLiP-5 Conference held in Warsaw, Poland, 30 November - 1 December 2002), 47-62. Warsaw: Inst. Podstaw Informatyki PAN.

Gvozdanović, Jadranka

1991 Syncretism and Paradigmatic Patterning of Grammatical Meaning. In F. Plank (ed.), Paradigms, 133-160. Berlin: Mouton de Gruyter.

Halle, Morris

1994 The Russian Declension: An Illustration of the Theory of Distributed Morphology. In J. Cole \& C. Kisseberth (eds.), Perspectives in Phonology, 29-60. Stanford: CSLI Publications.

Halle, Morris \& Alec Marantz

1993 Distributed Morphology and the Pieces of Inflection. In K. Hale \& S. J. Keyser (eds.), The View from Building 20, 111-176. Cambridge, Mass.: MIT Press. 
Hankamer, Jorge \& Judith Aissen

1974 The Sonority Hierarchy. In A. Bruck, R. Fox \& M. Labaly (eds.), Papers from the Parasession on Natural Phonology, 131-145. Chicago Linguistic Society, University of Chicago.

Harley, Heidi \& Rolf Noyer

1999 Distributed Morphology, GLOT International 4/4, 3-9.

Isačenko, Alexander

1975 Die russische Sprache der Gegenwart. München: Max Hueber Verlag.

Jakobson, Roman

1962a Beitrag zur allgemeinen Kasuslehre. Gesamtbedeutungen der russischen Kasus. In Selected Writings. Vol. 2, 23-71. The Hague and Paris: Mouton.

1962b Morfologičeskije Nabljudenija. In Selected Writings. Vol. 2, 154-181. The Hague and Paris: Mouton.

Kenstowicz, Michael

1994 Sonority-Driven Stress. Ms. MIT, Cambridge, Mass.

Kenstowicz, Michael \& Jerzy Rubach

1987 The Phonology of Syllabic Nuclei in Slovak, Language 63, 463-497.

Kiparsky, Paul

1973 "Elsewhere" in Phonology. In S. Anderson \& P. Kiparsky (eds.), A Festschrift for Morris Halle, 93-106. New York: Academic Press.

1982 From Cyclic Phonology to Lexical Phonology. In H. van der Hulst \& N. Smith (eds.), The Structure of Phonological Representations. Vol. 1, 131-175. Dordrecht: Foris.

Leskien, August

1955 Handbuch der altbulgarischen Sprache. (7th edn.) Heidelberg: Carl Winter Universitätsverlag.

Lieber, Rochelle

1992 Deconstructing Morphology. Chicago: University of Chicago Press.

Lumsden, John

1992 Underspecification in Grammatical and Natural Gender, Linguistic Inquiry 23, 469-486.

Matthews, Peter

1974 Morphology. Cambridge: Cambridge University Press.

McCreight, Katherine \& Catherine Chvany

1991 Geometric Representation of Paradigms in a Modular Theory of Grammar. In F. Plank (ed.), Paradigms, 91-111. Berlin: Mouton de Gruyter.

Müller, Gereon

1997 Beschränkungen für Binomialbildung im Deutschen, Zeitschrift für Sprachwissenschaft 16, 5-51.

2000 Elemente der optimalitätstheoretischen Syntax. Tübingen: Stauffenburg.

2002 Remarks on Nominal Inflection in German. In Ingrid Kaufmann \& Barbara Stiebels (eds.), More than Words: A Festschrift for Dieter Wunderlich, 113145. Berlin: Akademie Verlag.

2003 Zwei Theorien der pronominalen Flexion im Deutschen (Versionen Standard und Mannheim). Deutsche Sprache 30, 328-363. 
2004a Syncretism and Iconicity in Icelandic Noun Declensions: A Distributed Morphology Approach. Ms., IDS Mannheim. To appear in Yearbook of Morphology 2004.

2004b A Distributed Morphology Approach to Syncretism in Russian Noun Inflection. In Olga Arnaudova, Wayles Browne, Maria Luisa Rivero, \& Danijela Stojanovic (eds.), Proceedings of FASL 12, 353-373. Michigan Slavic Publications.

Neidle, Carol

1988

The Role of Case in Russian Syntax. Dordrecht: Kluwer.

Nesset, Tore

1994 A Feature-Based Approach to Russian Noun Inflection. Journal of Slavic Linguistics 2, 214-237.

Noyer, Rolf

$1997 \quad$ Features, Positions and Affixes in Autonomous Morphological Structure. New York: Garland Publishing.

Oltra Massuet, Isabel

1999 On the Notion of Theme Vowel: A New Approach to Catalan Verbal Morphology. Master of science thesis, MIT, Cambridge, Mass.

Plank, Frans

1979 Ikonisierung und De-Ikonisierung als Prinzipien des Sprachwandels, Sprachwissenschaft 4, 121-158.

2002 The Basic Questions of Inflection Classes, With Hints Towards Answers to Some. Ms., Universität Konstanz.

Prince, Alan

1996 Elsewhere and Otherwise, GLOT International 1, 23-24.

Prince, Alan \& Paul Smolensky

1993 Optimality Theory. Constraint Interaction in Generative Grammar. Book ms., Rutgers University.

Ross, John 1980 Ikonismus in der Phraseologie, Zeitschrift für Semiotik 2, 39-56.

Shapiro, Michael

1969 Aspects of Russian Morphology. Cambridge, Mass.: Slavica Publishers.

Steins, Carsten

1998 Against Arbitrary Features in Inflection: Old English Declension Classes. In W. Kehrein \& R. Wiese (eds.), Phonology and Morphology of the Germanic Languages, 241-265. Tübingen: Niemeyer.

Stump, Gregory

2001 Inflectional Morphology. Cambridge: Cambridge University Press.

Trommer, Jochen

2001 Distributed Optimality. Doctoral dissertation, Universität Potsdam.

Wiese, Bernd

1996 Iconicity and Syncretism. On Pronominal Inflection in Modern German. In R. Sackmann (ed.), Theoretical Linguistics and Grammatical Description, 323344. Amsterdam: Benjamins.

1999 Unterspezifizierte Paradigmen. Form und Funktion in der pronominalen Deklination, Linguistik Online 4. 
2001 Zur lateinischen Deklination: Die Form-Funktions-Beziehung. Ms., IDS Mannheim.

this volume Some Cases of Case Syncretism: On Russian Declension.

Williams, Edwin

1994 Remarks on Lexical Knowledge, Lingua 92, 7-34.

1997 Blocking and Anaphora, Linguistic Inquiry 28, 577-628.

Wunderlich, Dieter

1996 Minimalist Morphology: The Role of Paradigms. In G. Booij \& J. van Marle (eds.), Yearbook of Morphology 1995, 93-114. Dordrecht: Kluwer.

1997 Der unterspezifizierte Artikel. In C. Dürscheid, K. H. Ramers \& M. Schwarz (eds.), Sprache im Fokus, 47-55. Tübingen: Niemeyer.

this volume Is There Any Need for the Concept of Directional Syncretism?.

Wurzel, Wolfgang Ullrich

1984 Flexionsmorphologie und Natürlichkeit. Berlin: Akademie Verlag.

1998 Drei Ebenen der Struktur von Flexionsparadigmen. In R. Fabri, A. Ortmann $\&$ T. Parodi (eds.), Models of Inflection. Tübingen: Niemeyer.

Zifonun, Gisela

2001 Grammatik des Deutschen im europäischen Vergleich: Das Pronomen, Teil 1: Überblick und Personalpronomen. Amades working paper 4/01, IDS Mannheim.

2003 Aspekte deutscher Reflexivkonstruktionen im europäischen Vergleich: Pronominale Paradigmen und NP-interne Reflexiva. In L. Gunkel, G. Müller \& G. Zifonun (eds.), Arbeiten zur Reflexivierung, 267-300. Tübingen: Narr.

Zifonun, Gisela, Ludger Hoffmann, Bruno Strecker et al.

1997 Grammatik der deutschen Sprache. Berlin: de Gruyter.

Zwicky, Arnold

1970 Class Complements in Phonology, Linguistic Inquiry 1, 262-264.

1985 How to Describe Inflection. In M. Niepokuj, M. V. Clay, V. Nikiforidou \& D. Feder (eds.), Proceedings of the 11th Annual Meeting of the Berkeley Linguistics Society, 372-386. BLS, Berkeley, University of California.

1991 Systematic versus Accidental Phonological Identity. In F. Plank (ed.), Paradigms: The Economy of Inflection, 113-132. Berlin: Mouton de Gruyter. 